\title{
Two-Dimensional Model Calculation of Fluorine-Containing Reservoir Species in the Stratosphere
}

\author{
Jack A. Kaye, Anne R. Douglass, Charles H. Jackman, and Richard S. Stolarski \\ NASA Goddard Space Flight Center, Greenbell, Maryland \\ R. Zander, AND G. Roland \\ Institute of Astrophysics, University of Lidge, Liège-Ougré, Belgium
}

\begin{abstract}
Two-dimensional model calculations have been carried out of the distributions of the fluorinecontaining reservoir species $\mathrm{HF}, \mathrm{CF}_{2} \mathrm{O}$, and $\mathrm{CFClO}$. $\mathrm{HF}$ constitutes the largest fluorine reservoir in the stratosphere, but $\mathrm{CF}_{2} \mathrm{O}$ also makes an impurtant contribution to the inorganic fuorine budget. CFClO amounts are most important in the tropical lower stratosphere. HF amounts increase with altitude throughout the stratosphere, while those of $\mathrm{CF}_{2} \mathrm{O}$ and $\mathrm{CFClO}$ fall off above their mixing ratio peaks due to photolysis. The model is in good qualitative agreement with observed vertical profiles of $\mathrm{HF}$ and $\mathrm{CF}_{2} \mathrm{O}$ but tends to underestimate the total column of $\mathrm{HF}$. The calculated $\mathrm{CFClO}$ distribution is in good agreement with the very limited data. The disagreement in the HF columns is likely due to small inaccuracies in the model's treatment of lower stralospheric photolysis of chlorofluorocarbons. The model results support the suggestion that $\mathrm{CF}_{2} \mathrm{O}$ may be heterogeneously converted to HF on the surface of polar stratospheric cloud particles. The model results also suggest that the quantum yield for photolysis of $\mathrm{CF}_{2} \mathrm{O}$ is near unity.
\end{abstract}

\section{INTRODUCTION}

Concern about the possible implications of increasing amounts of chlorofluorocarbons (CFCs) on the amount of ozone $\left(\mathrm{O}_{3}\right)$ in the Earth's stratosphere has led to great interest in measuring the concentration of halogen-containing compounds in the stratosphere. The greatest attention for chlorine has been given to the catalytically active species chlorine monoxide ( $\mathrm{ClO}$ ) and the reservoir species chlorine nitrate $\left(\mathrm{ClONO}_{2}\right)$ and hydrogen chloride $(\mathrm{HCl})$, with less attention to others. For fluorine, which is not catalytically active in ozone destruction, most of the attention has gone to hydrogen fluoride (HF), the dominant fluorine reservoir species in the stratosphere. It is this dominance of $\mathrm{HF}$ in the stratospheric fluorine budget which prevents catalytic reactions involving fluorine-containing species leading to ozone destruction [Stolarski and Rundel, 1975].

Because HF plays such an important role in the chemistry of stratospheric fluorine, monitoring of its concentration has been used as a way of verifying the breakdown of CFCs in the stratosphere as predicted by atmospheric chemical models. A quantity of particular interest is the ratio of the columns of $\mathrm{HCl}$ and $\mathrm{HF}$. $\mathrm{HF}$ amounts are increasing faster than those of $\mathrm{HCl}$ [ $C h u$ et al., 1990], so this ratio is changing with time.

The largest long-term set of measurements of stratospheric HF columns is that of Zander and coworkers [Zander et al., 1987], who have made measurernents of the total column of atmospheric HF above Jungfraujoch, Switzerland, for over a decade. They have observed an annual increase of approximately 8 percent in the HF column. A long-term set of ground-based measurements of the HF column from Kitt Peak has been recently shown to have an annual increase of approximately 10.7 percent.

Copyright 1991 by the American Geophysical Union.

Paper number 91JD01178.

0148-0227/91/91JD-01178\$05.00
There have also been numerous measurements of the vertical profile of HF by balloons [Zander, 1981; Park et al., 1984; Carli and Park, 1988; Mankin et al., 1990b] and from the space shuttle with the atmospheric trace molecule spectroscopy (ATMOS) instrument [Raper et al., 1987; Zander et al., 1990] which flew on Spacelab 3 in April and May of 1985. There have further been measurements of the latitudinal dependence of the HF column measured from aircraft-borne infrared spectrometers [Girard et al., 1983; Mankin and Coffey, 1983; Karcher et al., 1988] and one mesurement of the HF column from Antarctic [Farmer et al., 1987]. More recently, measurements of HF column amounts in the Antarctic were measured by Toon et al. [1989] and Coffey et al. [1989] as part of the Airborne Antarctic Ozone Experiment (AAOE) in August-September 1987, and both groups made similar measurements in the Arctic as part of the Airborne Arctic Stratospheric Expedition (AASE) (G. C. Toon, private communication, $1990 ;$ W. G. Mankin and M. T. Coffey, private communication, 1990) in January-February 1989.

Other fluorine-containing reservoir species which have been measured in the stratosphere include both carbonyl fluoride $\left(\mathrm{CF}_{2} \mathrm{O}\right)$, which was measured with the ATMOS instrument, and chlorofluoroformaldehyde (CFClO), which was measured from samples taken during aircraft flights. The ATMOS measurements of $\mathrm{CF}_{2} \mathrm{O}$ [Rinsland et al., 1986; Raper et al., 1987] showed that an important fraction of the inorganic fluorine (that not bound to carbon in the form of CFCs) is present as $\mathrm{CF}_{2} \mathrm{O}$ through most of the lower and middle stratosphere. $\mathrm{CF}_{2} \mathrm{O}$ abundances have also been determined from infrared spectra taken during balloon flights in October 1979 and April 1989, suggesting an increase of some 10 percent per year [Rinsland et al., 1990]. In the CFClO measurements [Wilson et al., 1989], tropospheric mixing ratios were always found to be below the detection threshold of 4 pptv, while stratospheric mixing ratios seldom exceeded 20 pptv and neve- exceeded 30 pptv.

There have been few model calculations detailing the chemistry of the fluorine atoms released in the stratosphere 
following the breakdown of CFCs, however. The most complete efforts were those of Sze [1978] and of Crutzen et al. [1978], who used a one-dimensional model to examine the vertical distribution of $\mathrm{HF}, \mathrm{CF}_{2} \mathrm{O}$, and $\mathrm{CFClO}$. Sze [1978] found for 1977 maximum mixing ratios of $\mathrm{HF}, \mathrm{CF}_{2} \mathrm{O}$, and $\mathrm{CFClO}$ to be approximately $0.6,0.06$, and 0.01 parts per billion by volume, respectively, with the maximum mixing ratios for the latter two species occurring at 30 and $25 \mathbf{~ k m}$, respectively. Crutzen et al. [1978] found for 1976 maximum mixing ratios of approximately $0.4,0.06$, and $0.015 \mathrm{ppbv}$ for these species, with the region of maxima for $\mathrm{CF}_{2} \mathrm{O}$ and CFClO occurring near 40 and $25 \mathrm{~km}$, respectively.

The ATMOS data [Raper et al., 1987; Zander et al., 1990] from April-May 1985 showed no significant difference between the HF profiles obtained at $30^{\circ} \mathrm{N}$ and $47^{\circ} \mathrm{S}$ measured in May 1985, especially when the measurement uncertainties are considered. Solomon and Garcia [1984] simulated stratospheric HF distributions with their two-dimensional model, but neglected $\mathrm{CF}_{2} \mathrm{O}$ based on the results of $S z e$ [1978]. They showed evidence for an important seasonal dependence on mid-latitude ( 39 degree latitude) profiles with winter amounts being larger than summer ones by substantial amounts up to approximately $35 \mathrm{~km}$. The ground-based total column measurements from the Jungfraujoch [Zander et al., 1987] also show evidence of an important seasonal dependence; using 3-month running means for their 1983-1985 data, they found evidence for an annual cycle with a maximum in late spring and a minimum in fall, with an oscillation amplitude corresponding to approximately 10 percent above and below the annual mean.

Knowledge of the two-dimensional distribution of $\mathrm{HF}$ and its production and loss rates is important for performing three-dimensional simulations of HF in the stratosphere. Such calculations have been carried out for the AASE mission [Kaye et al., 1990] using a three-dimensional chemistrytransport model [Rood et al., 1989]. In Kaye et al. [1990] the needed data (initial condition, production, and loss rates) for HF were calculated with the two-dimensional photochemical model [Douglass et al., 1989] modified to include fluorine chemistry as described below. The two-dimensional distribution was then mapped to the three-dimensional initial condition with the procedure of Douglass et al. [1990].

In this paper we present the distributions of $\mathrm{HF}, \mathrm{CF}_{2} \mathrm{O}$, and CFClO calculated with the two-dimensional model. We focus on the vertical, meridional, and seasonal dependence of the concentrations of these compounds. We also consider the rate of increase of these compounds expected on the basis of the increase in the amounts of CFCs in the atmosphere, and we compare the results of our calculations to available measurements.

The outline of this paper is as follows. In the next section we review the two-dimensional model used in these calculations, the modifications made to implement fluorine chemistry, and the scenarios for CFC increase used. We present results in the following section and then compare them to available data. We close by summarizing our results.

\section{Model Calculations}

The two-dimensional (2-D) model used here is that of Douglass et al. [1989] and has been described in detail previously, so we review it only briefly here, focusing on additions to the chemistry needed for the more complete treat- ment of fluorine chemistry. The model has been applied extensively to a number of stratospheric problems, including the simulation of ozone distributions [Jackman et al., 1989a]. Comparisons of the results of this model with that of other 2-D models have been carried out and presented in a recent report [Jackman et al., 1989b]. A similar model has recently been applied to the chemistry of $\mathrm{HF}, \mathrm{CF}_{2} \mathrm{O}$, and $\mathrm{CFClO}$ in the stratosphere in a paper by C. P. Rinsland et al. (Infrared measurements of $\mathrm{HF}$ and $\mathrm{HCl}$ total column abundances above Kitt Peak, 1977-1990: Seasonal cycles, increases in total $\mathrm{HF}$, total $\mathrm{HCl}$, and the $\mathrm{HF} / \mathrm{HCl}$ total column ratio, and comparisons with two-dimensional model calculations, submitted to Journal of Geophysical Research, 1991).

The model covers the altitude range from the ground to approximately $60 \mathrm{~km}(0.23 \mathrm{mbar})$ with 30 levels equally spaced in log pressure. The latitude range is from $85^{\circ} \mathrm{S}$ to $85^{\circ} \mathrm{N}$ with a 10 -degree interval. Families are used in the calculation of the chemical production and loss terms where appropriate; source gases and some relatively longlived intermediate gases are transported separately, while most short-lived hydrogen- and carbon-containing free radicals are calculated using photochemical equilibrium approximations.

The calculations performed here require the addition of $\mathrm{HF}, \mathrm{CF}_{2} \mathrm{O}$, and $\mathrm{CFClO}$ as separately transported species. Formation is assumed to be due solely to the breakdown of CFCs; we neglect the suggested source of HF due to volcanic eruptions and passive outgassing [Symonds et al., 1988]. A crucial assumption made is that when CFCs break down in the stratosphere, the first bond broken is a carbonchlorine bond [Rebbert and Ausloos, 1975; DeMore et al., 1987], and that remaining $\mathrm{C}-\mathrm{Cl}$ bonds break before any C-F bonds do (this is based on consideration of the thermodynamics of the dissociation of halogen-substituted analogues of methyl radical [Baulch et al., 1980]). For hydrogencontaining CFCs (HCFCs) we assume the $\mathrm{C}-\mathrm{Cl}$ bond breaks after the $\mathrm{C}-\mathrm{H}$ bond but before any of the $\mathrm{C}-\mathrm{F}$ bonds. This lets us establish a clear correlation between source gases and reservoir species formed. With the exception of trichlorofluoromethane $\left(\mathrm{CFCl}_{3}\right.$, commonly abbreviated as $\mathrm{F}$-11) the most important CFCs all contain two or more fluorine atoms. We assume that the fluorine from these CFCs is preferentially incorporated in $\mathrm{CF}_{2} \mathrm{O}$, with any odd fluorine atoms being assumed to form $\mathrm{HF}$ directly. Since $\mathrm{CFCl}_{3}$ has only one fluorine atom, it is assumed to form CFClO.

This assumption is made by analogy with the wellknown $\mathrm{CH}_{4}$ oxidation scheme through the intermediates $\mathrm{CH}_{3}, \mathrm{CH}_{3} \mathrm{O}_{2}, \mathrm{CH}_{3} \mathrm{O}, \mathrm{CH}_{2} \mathrm{O}$, and $\mathrm{HCO}$.

For difluorodichloromethane $\left(\mathrm{CF}_{2} \mathrm{Cl}_{2}\right.$, commonly abbreviated as $\mathrm{F}-12$ ) the most abundant fluorine-containing source gas, the assumed oxidation pathway is as follows:

$$
\begin{aligned}
& \mathrm{CF}_{2} \mathrm{Cl}_{2}+h \nu \rightarrow \mathrm{CF}_{2} \mathrm{Cl}+\mathrm{Cl} \\
& \mathrm{CF}_{2} \mathrm{Cl}+\mathrm{O}_{2}+\mathrm{M} \rightarrow \mathrm{CF}_{2} \mathrm{ClO}_{2}+\mathrm{M} \\
& \mathrm{CF}_{2} \mathrm{ClO}_{2}+\mathrm{NO} \rightarrow \mathrm{CF}_{2} \mathrm{ClO}+\mathrm{NO}_{2} \\
& \mathrm{CF}_{2} \mathrm{ClO}+\mathrm{O}_{2} \rightarrow \mathrm{CF}_{2} \mathrm{O}+\mathrm{ClOO} \\
& \mathrm{CF}_{2} \mathrm{O}+h \nu \rightarrow \mathrm{F}+\mathrm{FCO} \\
& \quad \mathrm{F}_{2}+\mathrm{CO} \\
& \mathrm{FCO}+\mathrm{O}_{2} \rightarrow \mathrm{FC}(\mathrm{O}) \mathrm{O}_{2} \rightarrow \mathrm{FO}+\mathrm{CO}_{2}
\end{aligned}
$$

The FO formed following the dissociation of the $\mathrm{FC}(\mathrm{O}) \mathrm{O}_{2}$ complex formed in the reaction of $\mathrm{FCO}$ with $\mathrm{O}_{2}$ [Francisco et al., 1988] is assumed to be rapidly converted to $F$, which 
then forms $\mathrm{HF}$ immediately by reaction with $\mathrm{H}_{2} \mathrm{O}$ or $\mathrm{CH}_{4}$. $F_{2}$ is assumed to rapidly photolyze to $F$. Thus each molecule of $\mathrm{CF}_{2} \mathrm{Cl}_{2}$ is assumed to break down to form one molecule of $\mathrm{CF}_{2} \mathrm{O}$, while photolysis of $\mathrm{CF}_{2} \mathrm{O}$ is assumed to lead to formation of two HF molecules.

The corresponding pathway for $\mathrm{CFCl}_{3}$, the other most important fluorine-containing source gas, is as follows:

$$
\begin{aligned}
& \mathrm{CFCl}_{3}+h \nu \rightarrow \mathrm{CFCl}_{2}+\mathrm{Cl} \\
& \mathrm{CFCl}_{2}+\mathrm{O}_{2}+\mathrm{M} \rightarrow \mathrm{CFCl}_{2} \mathrm{O}_{2}+\mathrm{M} \\
& \mathrm{CFCl}_{2} \mathrm{O}_{2}+\mathrm{NO} \rightarrow \mathrm{CFCl}_{2} \mathrm{O}+\mathrm{NO}_{2} \\
& \mathrm{CFCl}_{2} \mathrm{O}+\mathrm{O}_{2} \rightarrow \mathrm{CFClO}+\mathrm{ClO}_{2} \\
& \mathrm{CFClO}+h \nu \rightarrow \mathrm{Cl}+\mathrm{FCO}
\end{aligned}
$$

We neglect here the possible role of halogenated peroxy nitrates, which could be formed by the three-body recombination of $\mathrm{CF}_{2} \mathrm{Cl}$ or $\mathrm{CFCl}_{2}$ with $\mathrm{NO}_{2}$. These reactions have been observed in the laboratory by Lesclaux and Caralp [1984] for $\mathrm{CFCl}_{2}$ and by Moore and Carr [1990] for $\mathrm{CF}_{2} \mathrm{Cl}$. The nitrate $\mathrm{CFCl}_{2} \mathrm{O}_{2} \mathrm{NO}_{2}$ formed from $\mathrm{CFCl}_{2}$ has been considered previously by Lesclaux et al. [1986] in terms of its impact on stratospheric chlorine chemistry. They found that at most several percent of the chlorine in the stratosphere would be present in the form of this nitrate. They argue that the nitrate of $\mathrm{CF}_{2} \mathrm{Cl}$ should be even less important because $\mathrm{CF}_{2} \mathrm{Cl}_{2}$ is photolyzed higher in the stratosphere than is $\mathrm{CFCl}_{3}$. The halogenated peroxynitrate $\mathrm{CF}_{2} \mathrm{ClO}_{2} \mathrm{NO}_{2}$ formed would be photolnyed more rapidly than is the $\mathrm{CFCl}_{2} \mathrm{O}_{2} \mathrm{NO}_{2}$.

Absorption cross sections for $\mathrm{CF}_{2} \mathrm{O}$ and $\mathrm{CFClO}$ are taken from the compilation of DeMore et al. [1987] with unit quantum yield assumed. This assumption has not been verified in the laboratory. We also allow for removal of $\mathrm{CF}_{2} \mathrm{O}$ and $\mathrm{CFClO}$ by reaction with $\mathrm{O}\left({ }^{1} D\right)$; for the former, we use the rate of Wine and Ravishankara [1983] of $2.1 \times 10^{-11} \mathrm{~cm}^{3}$ molecule $e^{-1} \mathrm{~s}^{-1}$ for chemical reaction, while for the latter we use the tabulated value of $1.9 \times 10^{-10} \mathrm{~cm}^{3}$ molecule ${ }^{-1} \mathrm{~s}^{-1}$ [DeMore et al., 1987]. In using this rate we assume that chemical reaction accounts for the total deactivation rate of $\mathrm{O}\left({ }^{1} D\right)$ by $\mathrm{CFClO}$ and $\mathrm{CF}_{2} \mathrm{O}$ (for example, there is no collisional quenching to ground state atomic oxygen). This assumption is justified to at least some extent by the observation that in collisions of $O\left({ }^{1} D\right)$ with most chlorinated organics chemical reaction dominates over physical quenching (see footnote A10 in the work by DeMore et al. [1987]). We assume that all the fluorinecontaining species considered here ( $\mathrm{HF}, \mathrm{CF}_{2} \mathrm{O}, \mathrm{CFClO}$ ) are rained out in the troposphere at the same rate as other soluble species. The 2-D model calculates daytime concentrations; since these species are expected to have very little or no diurnal variation, the daytime concentrations should be directly comparable to observational data regardless of time of measurement.

Time-dependent calculations were carried out for the period 1960-1990. Tropospheric mixing ratios based on the scenarios described in detail in a recent international report [World Meteorological Organization (WMO), 1990] were used in these calculations. Briefly, from 1960-1985 emissions of $\mathrm{CFCl}_{3}, \mathrm{CF}_{2} \mathrm{Cl}_{2}$, and several less abundant CFCs and also bromine-containing halons were taken from estimated productions. Constant production levels were assumed for 1985-1990. a slow but sustained growth was expected for $\mathrm{CHClF}_{2}$. Observed trends in $\mathrm{CO}_{2}, \mathrm{CH}_{4}, \mathrm{~N}_{2} \mathrm{O}$, $\mathrm{CCl}_{4}$, and $\mathrm{CH}_{3} \mathrm{CCl}_{3}$ were expected to continue. $\mathrm{CH}_{3} \mathrm{Cl}$ and $\mathrm{CH}_{3} \mathrm{Br}$ were held fixed.

\section{REsULTS}

\section{General Morphology of Calculated Distributions}

The mixing ratios of $\mathrm{HF}, \mathrm{CF}_{2} \mathrm{O}$, and $\mathrm{CFClO}$ calculated for March and June of 1989 as a function of latitude and altitude (assuming unit quantum yield for photodissociation in the photolysis of $\mathrm{CF}_{2} \mathrm{O}$ ) are shown in Figure 1. There are several important features in the distributions shown for March. First, the maximum values of the mixing ratios for $\mathrm{HF}, \mathrm{CF}_{2} \mathrm{O}$, and $\mathrm{CFClO}$ are approximately $1,0.25$, and 0.1 ppbv, respectively. The maxime are located at different altitudes, however. The largest mixing ratios of HF are found in the mesosphere (pressure less than 1.0 mbar), whereas those of $\mathrm{CF}_{2} \mathrm{O}$ and $\mathrm{CFClO}$ are found in the upper ( 4 mbar) and middle stratosphere (20 mbar), respectively. All three constituents have smaller mixing ratios in the lower stratosphere in the tropics than at high latitudes; for HF this continues into the mesosphere. In the lower stratosphere the mixing ratios of $\mathrm{CF}_{2} \mathrm{O}$ and $\mathrm{CFClO}$ have a minimum with respect to latitude in the tropics; in the upper stratosphere the maximum mixing ratios occur there.

These patterns may be simply understood in terms of stratospheric dynamics and the chemistry of these molecules and their precursors, the CFCs. Since the CFCs enter the stratosphere largely through upward motion in the tropics and are photolyzed weakly there because of the large overlying column of ozone, small mixing ratios of their breakdown products (including $\mathrm{HF}, \mathrm{CF}_{2} \mathrm{O}$, and $\mathrm{CFClO}$ ) are expected in the tropical lower stratosphere. As altitude increases, the CFCs dissociate and the various breakdown products form. $\mathrm{CFClO}$, which forms from photolysis of $\mathrm{CFCl}_{3}$, the $\mathrm{CFC}$ photolyzed lowest in the stratosphere, will be the breakdown product formed lowest in the stratosphere. Since it is also the most easily photolyzed F-containing breakdown product, its mixing ratio will fall off rapidly with increasing altitude above its peak.

$\mathrm{CF}_{2} \mathrm{O}$ is formed higher in the stratosphere following the photolysis of $\mathrm{CF}_{2} \mathrm{Cl}_{2}$ and is photolyzed more slowly than is CFClO. Its maximum mixing ratio occurs higher in the stratosphere than does that of $\mathrm{CFClO}$, and its decrease with altitude above its peak is much more gradual. Nonnegligible mixing ratios of $\mathrm{CF}_{2} \mathrm{O}$ are calculated to persist into the mesosphere.

Since HF is not photolyzed or otherwise lost by chemical reaction, its mixing ratio will continue to increase with altitude in the stratosphere and mesosphere until all the $\mathrm{CF}_{2} \mathrm{O}$ has been photolyzed. Then a constant mixing ratio is expected as long as vertical mixing is sufficiently rapid.

There is little difference in the CFClO distribution between the northern and southern hemisphere at the March equinox, but there are larger asymmetries in the $H F$ and $\mathrm{CF}_{2} \mathrm{O}$ distributions. For $\mathrm{HF}$ one sees the minimum mixing ratios occurring slightly south of the equator, but much larger middle and upper stratospheric mixing ratios are found in the northern (spring) hemisphere than in the southern (autumn one). For example, the $10 \mathrm{mbar}$ mixing ratio at $85^{\circ} \mathrm{N}$ is slightly above $0.9 \mathrm{ppbv}$, while that at $85^{\circ} \mathrm{S}$ is approximately 0.65 ppbv.

Some aspects of the seasonal dependence of the distributions of these compounds may be seen by considering the June 1989 mixing ratios also shown in Figure 1. There is only a small northward change in the distribution of $\mathrm{CF}$ $\mathrm{ClO}$, but there are larger changes in both $\mathrm{CF}_{2} \mathrm{O}$ and $\mathrm{HF}$. 

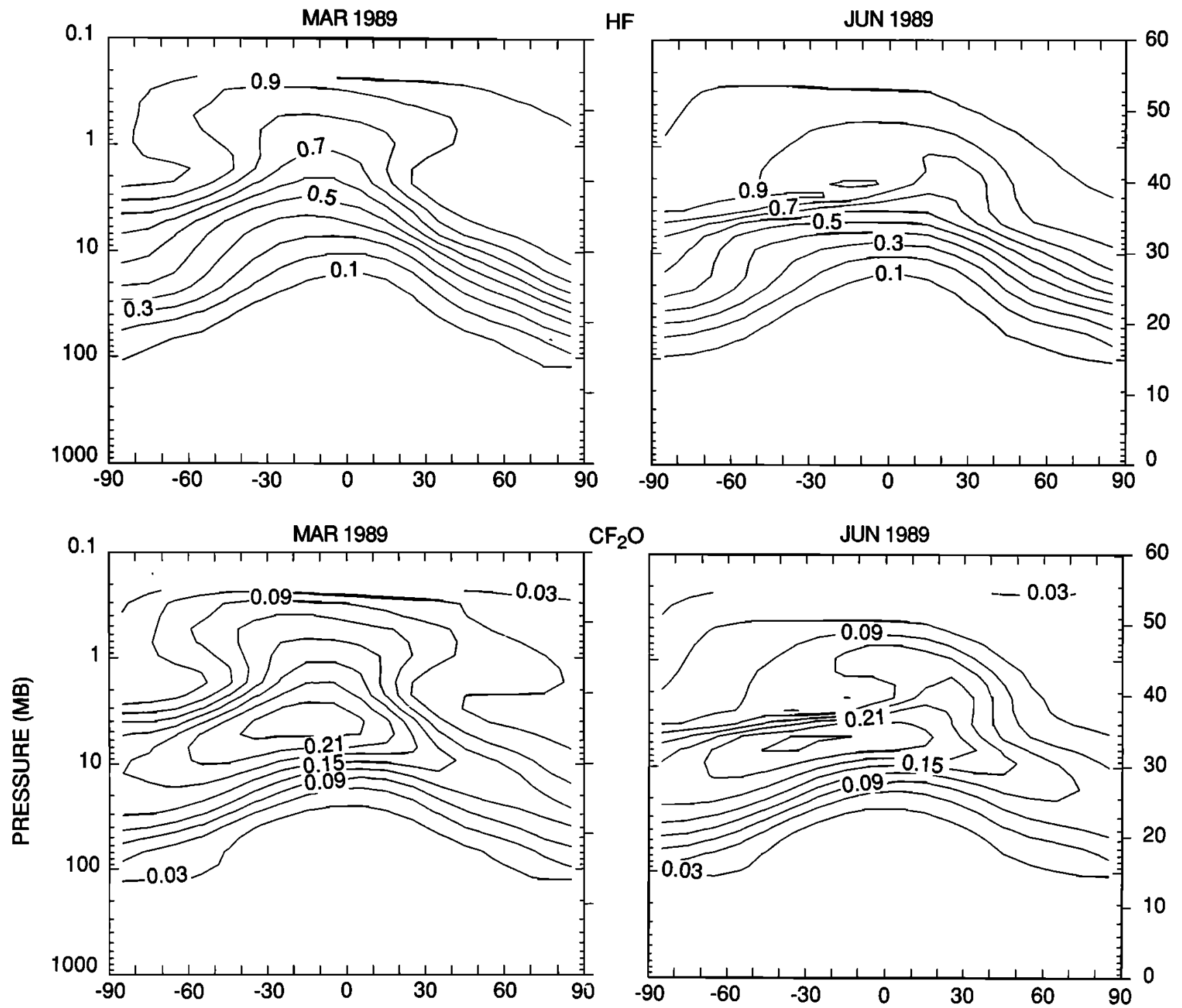

$\mathrm{CF}_{2} \mathrm{O}$

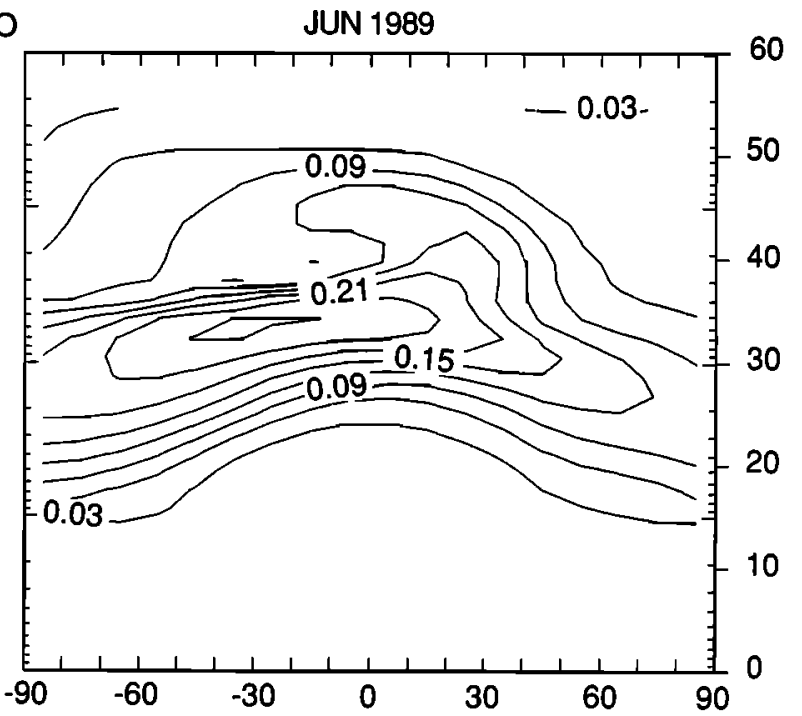

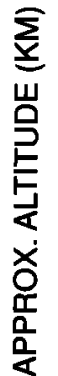

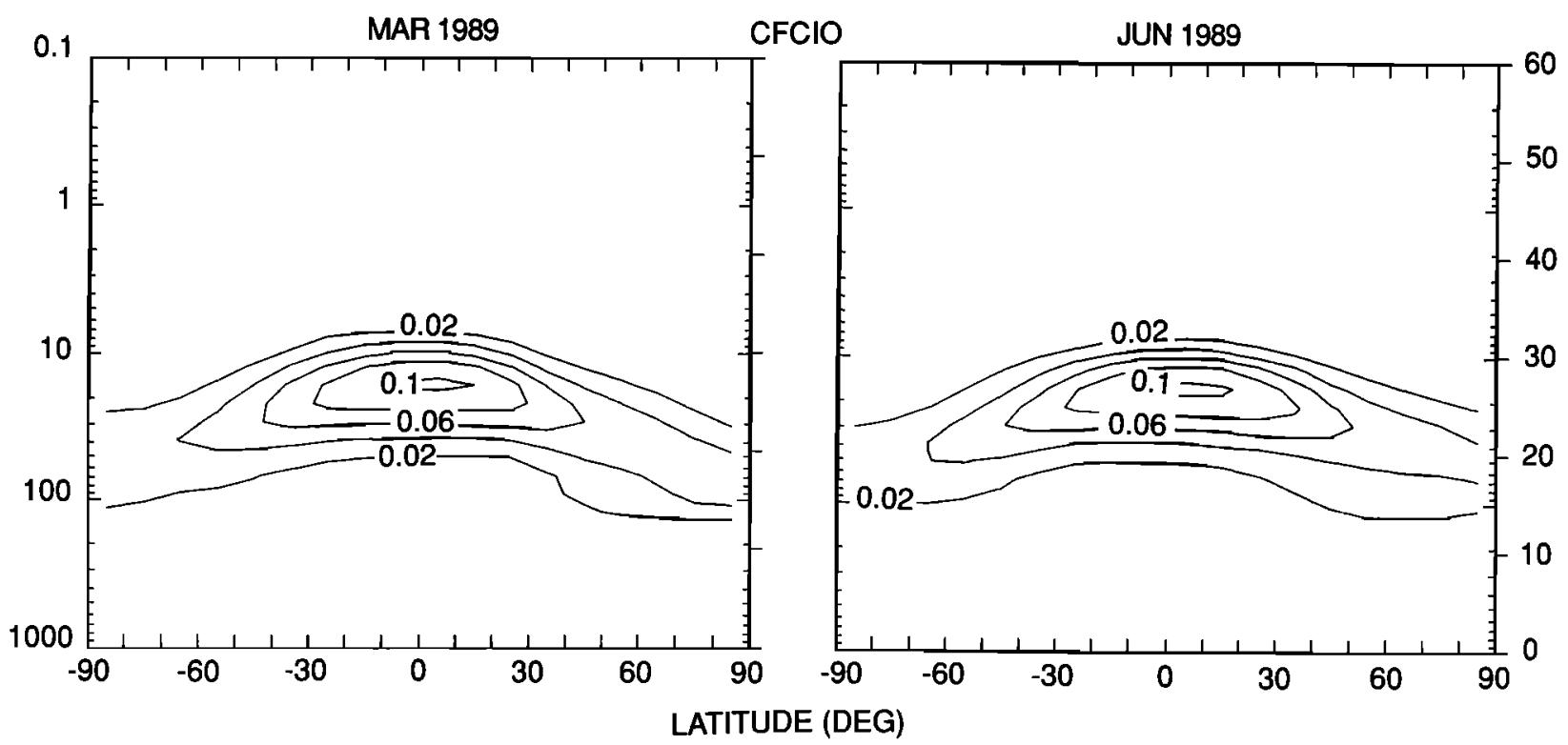

Fig. 1. Lalitude-altitude distributions for (top) $\mathrm{HF}$, (middle) $\mathrm{CF}_{2} \mathrm{O}$, and (bottom) CFClO for (left) March and (right) June of 1989 calculaled with the 2-D model. Contour intervals are 0.1 ppbv for $\mathrm{HF}, 0.03$ ppbv for $\mathrm{CF}_{2} \mathrm{O}$, and $0.02 \mathrm{ppbr}$. for $\mathrm{CFClO}$. 
In $\mathrm{CF}_{2} \mathrm{O}$ the midstratospheric mixing ratio peak narrows and moves strongly into the southern (winter) hemisphere, now being centered at approximately $30^{\circ} \mathrm{S}$. A large region of small gradients in both the vertical and meridional direction was found to occur near the stratopause in the winter hemisphere. A similar region of small gradients is found for $\mathrm{HF}$ in that part of the stratosphere as well; the minimum mixing ratio in the tropics has narrowed appreciably and moved to sub-tropical latitudes in the northern (summer) hemisphere.

Vertical profiles of the three F-containing constituents calculated for March 1989 at a tropical $\left(5^{\circ} \mathrm{N}\right)$, mid-latitude (45 $\left.{ }^{\circ} \mathrm{N}\right)$, and high-latitude $\left(85^{\circ} \mathrm{N}\right)$ region are shown in Figure 2 together with their relative contribution to the total inorganic fluorine (defined as the sum $\mathrm{HF}+2 \mathrm{CF}_{2} \mathrm{O}+\mathrm{CFClO}$ ). Several key features stand out from these figures. First, HF is the most important reservoir species for fluorine in the middle and upper stratosphere. This importance increases at higher latitudes. The role of the other reservoir species varies substantially with latitude. In the tropics, CFClO is calculated to be the most abundant F-containing reservoir species between approximately 80 and 20 mbar. The combined role of these compounds is sufficiently large that HF makes the largest contribution to total inorganic fluorine only above approximately 5 mbar. $\mathrm{CF}_{2} \mathrm{O}$ is an important component of the stratospheric fluorine budget in the lower and middle stratosphere, especially in the tropics and at mid-latitudes.

The seasonal and meridional dependence of the total column of these constituents are shown in Figure 3. There is a gross similarity in the total columns of all three; maxima are found at high latitudes and in the late winter - early spring. The amounts again descend in the sequence HF, $\mathrm{CF}_{2} \mathrm{O}, \mathrm{CFClO}$ in a ratio of aproximately 10:2:1 considering the local and seasonal maxima. The strength of the meridional gradients in the total column (defined as the ratio of the maximum polar value to the maximum tropical value) has a similar dependence, being approximately 5 for HF, 3 for $\mathrm{CF}_{2} \mathrm{O}$, and 1.5 for $\mathrm{CFClO}$. The meridional dependence of CFClO, especially in the southern hemisphere, is quite weak.

The relationship between the seasonal and meridional dependence of the columns of these three constituents may also be seen in this figure. The strength of the meridional gradient of $\mathrm{HF}$ is evidenced by the fact that its high-latitude value is some 5-10 times that of $\mathrm{CF}_{2} \mathrm{O}$ or CFClO, while the tropical value is only approximately twice that of the others. The large seasonal dependence in the HF column is also very clear; the maximum northern night latitude just above $1.1 \times 10^{15}$ molecule $\mathrm{cm}^{-2}$ at $85^{\circ} \mathrm{N}$ drops by approximately one third to $0.7 \times 10^{15}$ molecule $\mathrm{cm}^{-2}$ in September. The annual cycle in the southern high-latitude column is substantially smaller than that in the northern hemisphere. $\mathrm{CF}_{2} \mathrm{O}$ has larger columns in the high-latitude southern hemisphere than it does in the northern hemisphere; this is true for all months sampled.

\section{Comparison to Observations}

The observed vertical profiles of $\mathrm{HF}$ and $\mathrm{CF}_{2} \mathrm{O}$ most suited for comparison with the results of the 2-D model are those determined with the ATMOS instrument during its flight on the space shuttle in late April to early May of 1985. Two sunset measurements were made near $30^{\circ} \mathrm{N}$ (one at 31.5
${ }^{\circ} \mathrm{N}, 336.6^{\circ} \mathrm{W}$ on April 30, 1985. and the other at $26.58^{\circ} \mathrm{N}, 7.4$ ${ }^{\circ} \mathrm{W}$ on May 1, 1985). A sunrise measurement was also made at $47.15^{\circ} \mathrm{S}$ and $4.2^{\circ} \mathrm{W}$ [Raper et al., 1987; Zander et al., 1990]. The average of the two sunset measurements of $\mathrm{HF}$ is plotted in Figure 4 as plus signs; the corresponding vertical profile for $\mathrm{CF}_{2} \mathrm{O}$ (based on three sunset occultations) is shown in the figure by asterisks. The uncertainty (one standard deviation) in the observed values for HF were typically on the order of 15 percent, while those for $\mathrm{CF}_{2} \mathrm{O}$ were some 30 percent up to $30 \mathrm{~km}$, increasing to 50 percent at $40 \mathrm{~km}$ where the $\mathrm{CF}_{2} \mathrm{O}$ mixing ratios have decreased to one - half their peak values.

Calculated profiles from the 2-D model (averages of the $25^{\circ} \mathrm{N}$, April $1985,35^{\circ} \mathrm{N}$, April 1985, $25^{\circ} \mathrm{N}$, May 1985 , and $35^{\circ} \mathrm{N}$, May 1985 values) for these constituents, as well as CFClO, are also shown in Figure 4. The model simulates the observed HF mixing ratio of $0.7-0.8 \mathrm{ppbv}$ above approximately 5 mbar $(35 \mathrm{~km}$ )' but underestimates the $\mathrm{HF}$ mixing ratios in the lower and middle stratosphere ( $70-7 \mathrm{mbar}$ ). The observed $\mathrm{CF}_{2} \mathrm{O}$ mixing ratio is larger than that calculated in the lower stratosphere and smaller in the upper stratosphere (where the observations show $\mathrm{CF}_{2} \mathrm{O}$ falling off with altitude more rapidly than suggested by the model); the peak region near $\mathbf{1 0}$ mbar is reasonably well represented by the model, however.

Other vertical profiles provide far less similar structure to the calculated ones. For example, profiles measured by Park et al. [1984] over Broken Hill, Australia, and Hollomon Air Force Base (AFB), N.M. in March 1977 and October 1978, respectively, show nearly constant mixing ratios from 25$37 \mathrm{~km}$ (with an increase above $37 \mathrm{~km}$ ), with the Hollomon AFB values being some 50 percent larger than the Broken Hill ones. The model results do not show the HF mixing ratio becoming independent of altitude until approximately $40 \mathrm{~km}$.

Profiles measured in the BIC-2 campaign near Palestine, Tex. in June also differ substantially from those calculated here [Mankin et al., 1990b]. In the BIC-2 campaign, two far infrared emisssion instruments were used to determine the HF vertical profile. One found a maximum mixing ratio near $35 \mathrm{~km}$ of approximately $0.5 \mathrm{ppbv}$ with a small decrease at higher levels; the error bars on these measurements are sufficiently large, however, that a constant mixing ratio in (and slightly below) this altitude range is possible. The other instrument, found a maximum mixing ratio of approximately 0.5 ppbv near $37 \mathrm{~km}$. An infrared absorption measurement was compatible with a constant HF mixing ratio of slightly over $0.5 \mathrm{ppbv}$ above approximately $34 \mathrm{~km}$. The calculated profiles suggest that HF mixing ratios near $45 \mathrm{~km}$ of 0.6 ppbv are probable and that the mixing ratio might continue to increase into the lower mesosphere to values as large as 0.75 ppbv.

One vertical profile which was similar to the modelpredicted one was that of Carli and Park, measured in Palestine, Tex., in April 1979 [Carli and Park, 1988]. They found mixing ratios of $0.2,0.39$, and $0.36 \mathrm{ppbv}$ at 28,35 , and 38 $\mathrm{km}$, respectively. The 2-D model results for April 1979 show a $40-\mathrm{km}$ mixing ratio of approximately $0.4 \mathrm{ppbv}$ and one at $30 \mathrm{~km}$ of $0.2 \mathrm{ppbv}$; the rate of increase of the HF mixing ratio with altitude for the lower and middle stratopshere decreases substantially at about 5 mbar $(35 \mathrm{~km})$.

The most extensive set of measurements of the stratospheric HF column were made from aircraft at approxi- 

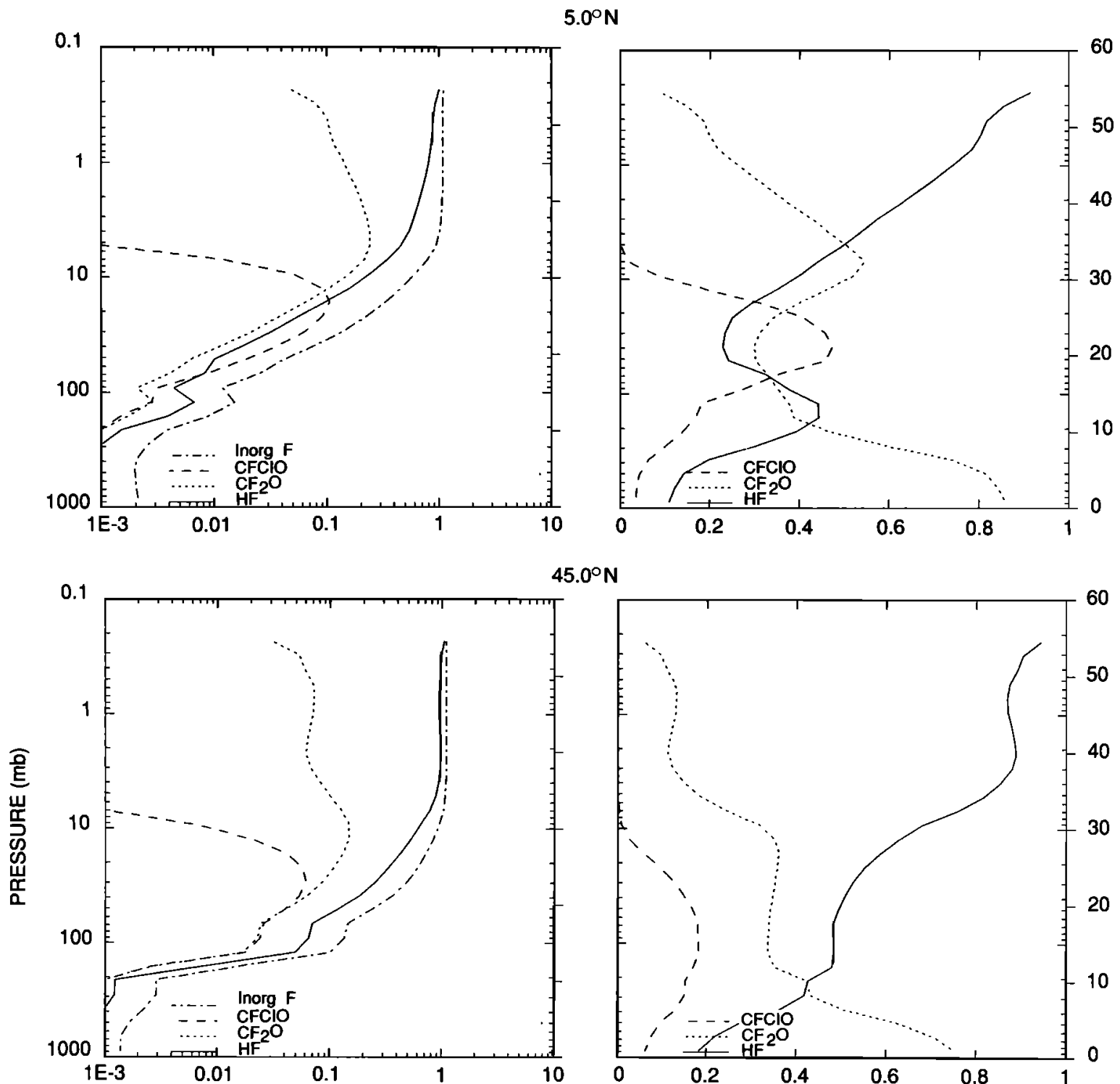

$45.0^{\circ} \mathrm{N}$

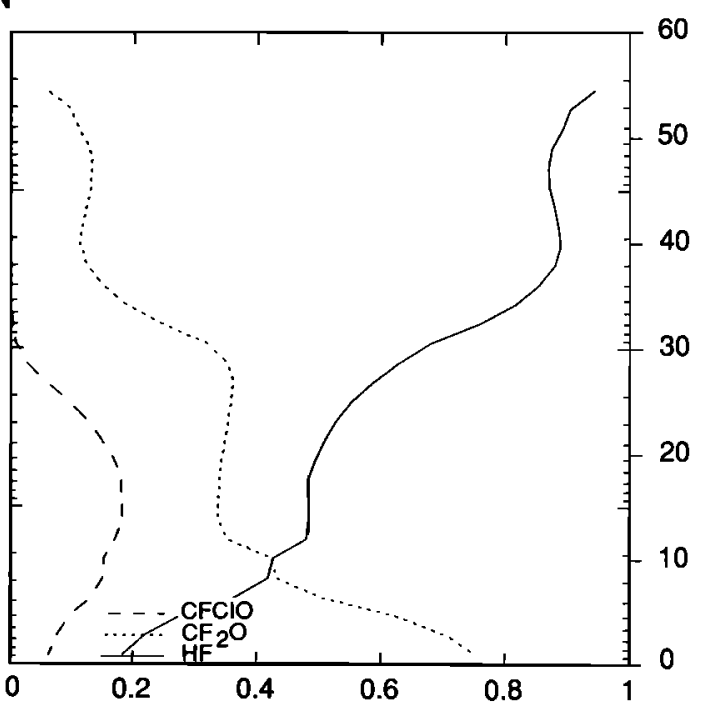

$85.0^{\circ} \mathrm{N}$
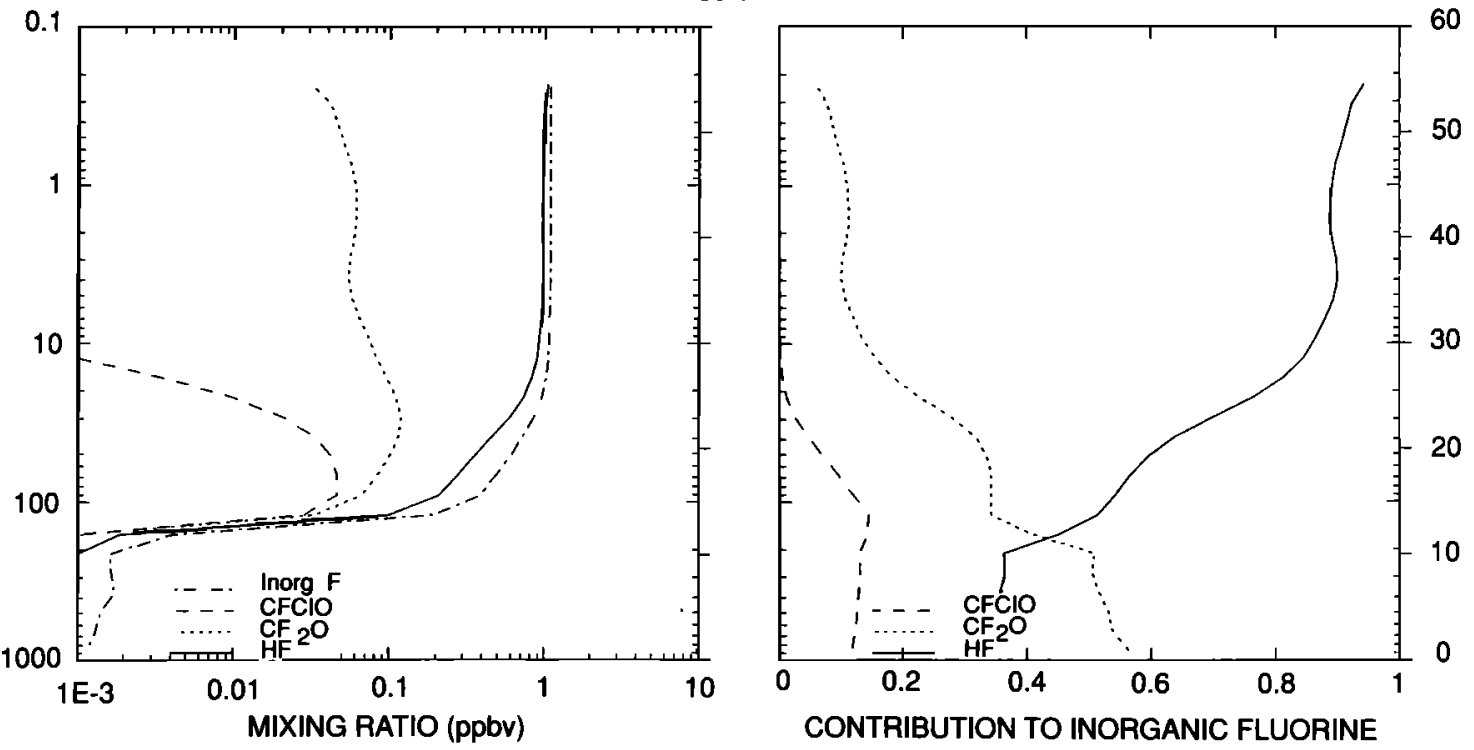

Fig. 2. lertical profiles of $\mathrm{HF}$ (solid line), $\mathrm{CF}_{2} \mathrm{O}$ (dotted line), and $\mathrm{CFClO}$ (dashed line), and total inorganic fluorine (dashed-dotted line) mixing ratios at (topleft) $5 \circ \mathrm{N}$, (middle left) $45^{\circ} \mathrm{N}$, and (bottom left) $85^{\circ} \mathrm{N}$ calculated for March 1989. The fractional contributions to the total inorganic fluorine are shown in the right panel for each latitude. 


\section{COLUMNS FOR $1989\left(10^{15}\right.$ molec $\left.\mathrm{cm}^{-2}\right)$}
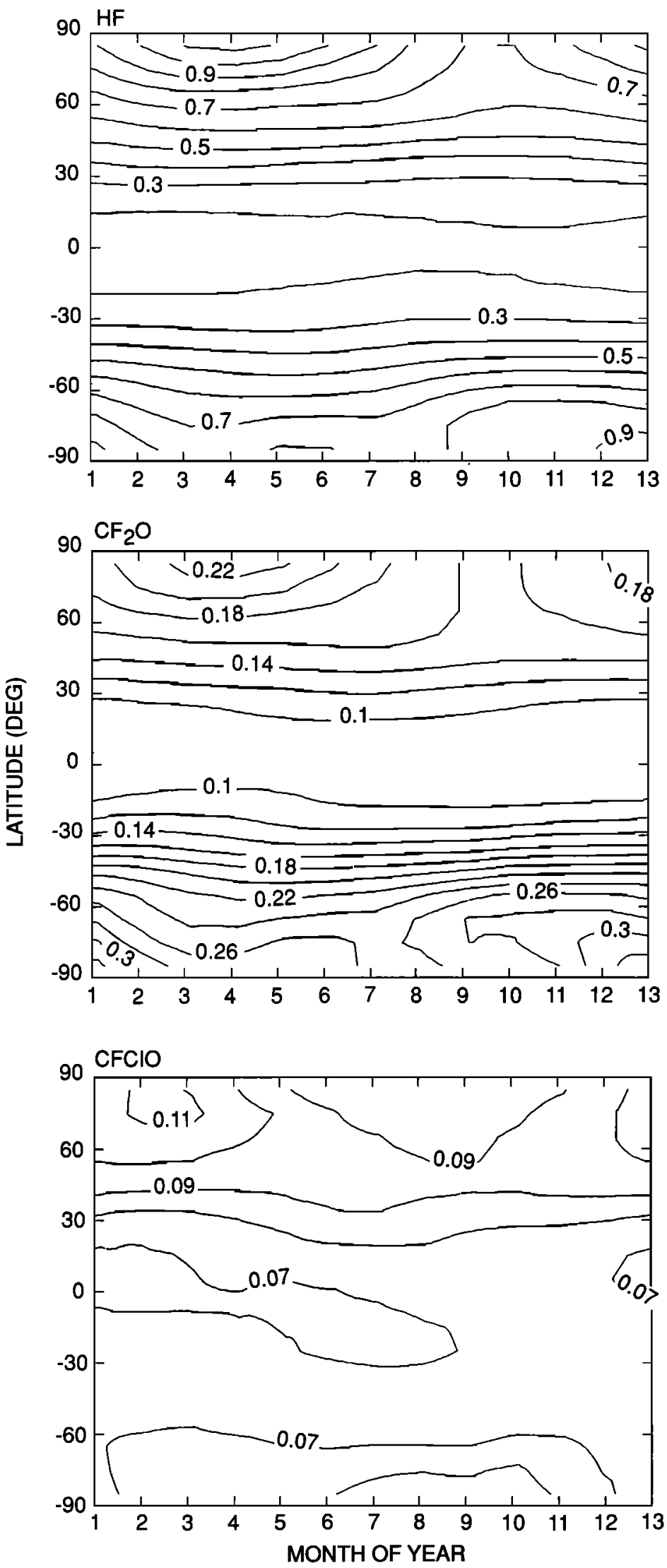

Fig. 3. Contusur plot of vericical columns of (top) HF, (middle) $\mathrm{CF}_{2} \mathrm{O}$, and (bottom) $\mathrm{CFClO}$ as a function of latitude and season caclulated for calendar vear 1989 . Contours are in units of $10^{15}$ molecule $\mathrm{cm}^{-2}$. Cuntour interval is 0.1 for $\mathrm{HF}, 0.02$ for $\mathrm{CF}_{2} \mathrm{O}$, and $0.01 \mathrm{fo}$ CFClO. mately 200 mbar by Mankin and Coffey [1983]. These measurements, covering the latitude range of $18.3^{\circ}-70.8^{\circ} \mathrm{N}$, were made over the time period from February 1, 1978 to July 25,1982 . They found that these data could be reasonably well represented by a curve of the form

$$
y=a+b \cos (\text { lat })
$$

where $y$ is the observed HF column in molecule $\mathrm{cm}^{-2}$ lat is the latitude, and $a$ and $b$ are parameters found to have values of $6.35 \times 10^{14}$ and $5.00 \times 10^{14}$ molecule $\mathrm{cm}^{-2}$, respectively.

A similar dependence of the model calculated column for this time period may be seen in the results shown in Figure 5 for March 1980, which is nearly halfway through the period of data reported by Mankin and Coffey [1983]. The calculated meridional dependence of the HF column (solid line) is fairly well represented as a linear function of the cosine of the latitude; the line obtained with the paramters calculated by Mankin and Coffey [1983] is shown with a dasheddotted line. Similar behavior is predicted for the meridional dependence of the columns of $\mathrm{CF}_{2} \mathrm{O}$ and $\mathrm{CFClO}$, although their absolute magnitudes and latitudinal variation are much smaller.

The 2-D model suggests, however, that the linear dependence of the HF column on the cosine of the latitude is not valid year round. For example, in 1989 the linear dependence was calculated for March (see Figure 6a), with values of the slope and intercept being approximately twice those in 1980 (see Figure 5). In September, on the other hand (see Figure 6b), there is marked curvature in the plot of the HF column versus cosine of latitude, especially in the range of $\cos ($ lat $)=0.5-0.7$ (latitude from $30^{\circ}-45^{\circ} \mathrm{N}$ ). A similar result was found for $\mathrm{CF}_{2} \mathrm{O}$; in March the column increased everywhere from the equator to the pole, while in September the column was found to vary only slightly northward of approximately $45^{\circ} \mathrm{N}$.

Recently, there have been a number of aircraft measurements of the HF column at high latitudes as part of the AAOE and AASE missions. Measurements were made with two instruments, the National Center for Atmospheric Research (NCAR) FTIR spectrometer [Coffey et al., 1989] and the Jet Propulsion Laboratory (JPL) MARK-IV interferometer [Toon et al., 1989]. The measurements from the two instruments differed in absolute magnitude but had similar dependence on time and aircraft position; the temporal and latitudinal dependence of the measurements greatly exceeded the estimated uncertainty in the measurements. For example, in the JPL measurements there is typically less than a 10 percent uncertainty (one sigma) associated with random error.

The NCAR group [Coffey et al., 1989] typically found HF columns between 0.7 and $1.0 \times 10^{15}$ molecule $\mathrm{cm}^{-2}$ in flights south of $65^{\circ} \mathrm{S}$, while the JPL group [Toon et al., 1989] found values between 1.0 and $1.6 \times 10^{15}$ molecule $\mathrm{cm}^{-2}$. Both groups found appreciably smaller HF columns over midlatitudes than nearer the poles. Toon et al. [1989] measured columns of approximately $0.7 \times 10^{15}$ molecule $\mathrm{cm}^{-2}$ between $28^{\circ}$ and $36^{\circ} \mathrm{S}$ on October 2, 1987, compared to values between 1.3 and $1.5 \times 10^{15}$ molecule $\mathrm{cm}^{-2}$ on September 26, 1987, near $65^{\circ} \mathrm{S}$; Coffey et al. [1989] found values of 0.37-0.49 $\times 10^{15}$ molecule $\mathrm{cm}^{-2}$ on October 2, 1987, compared to $0.7-0.8 \times 10^{15}$ molecule $\mathrm{cm}^{-2}$ on September 26, 1987, poleward of $70^{\circ} \mathrm{S}$. The latter also found values of $0.4 \times 10^{15}$ molecule $\mathrm{cm}^{-2}$ between $36^{\circ}$ and $44^{\circ} \mathrm{S}$ on August 22, 1987, compared to almost twice that at $73^{\circ} \mathrm{S}$ on August 28, 1987. 


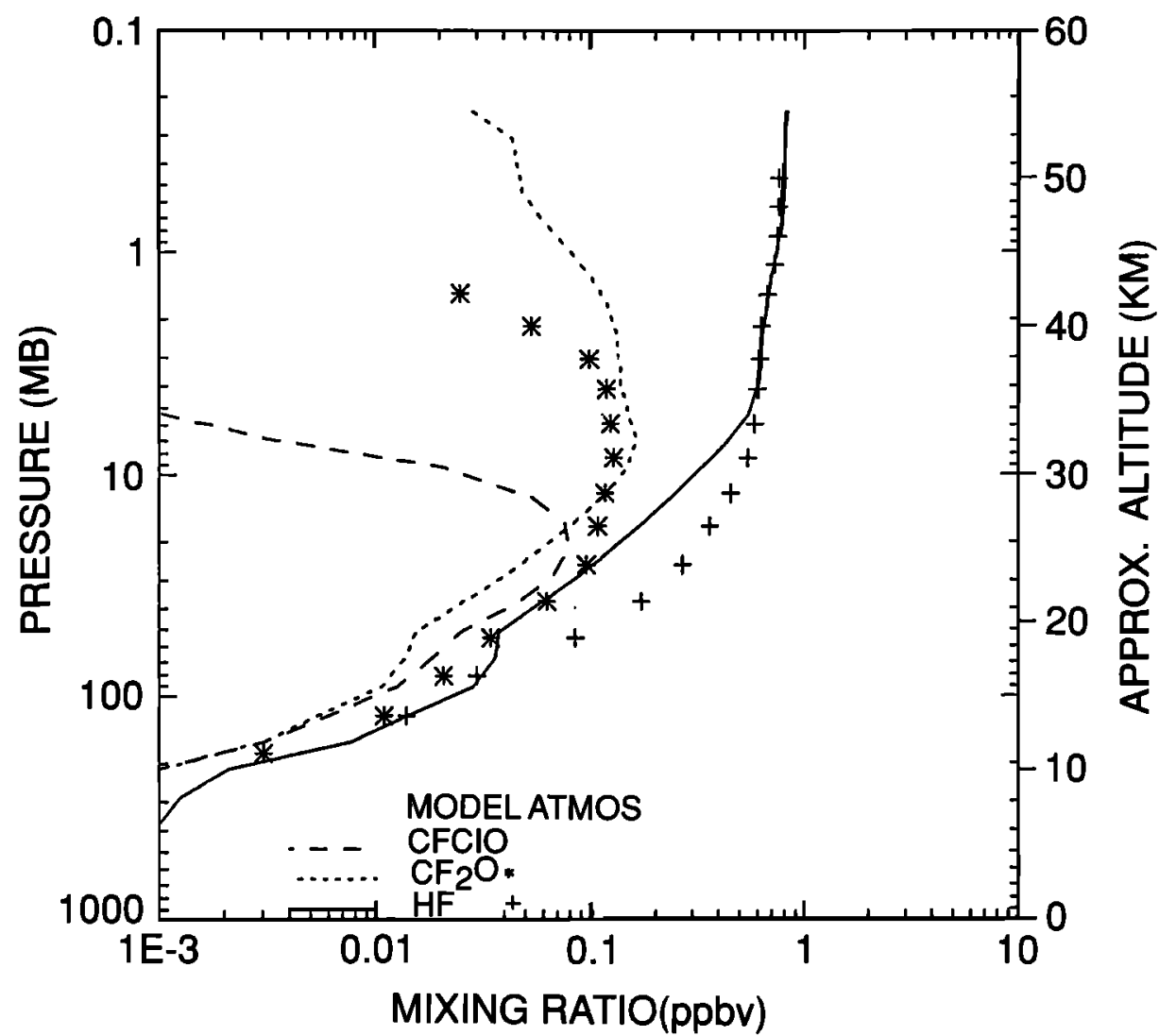

Fig. 1. lcrtical profile of $\mathrm{HF}$ (plus signs) and $\mathrm{CF}_{2} \mathrm{O}$ (asterisks) measured by ATMOS [Rinsland et al., 1986; Raper et al., 1987; Zander et al., 1990; R. M. Zander et al., unpublished manuscript] and 2-D model calculated profiles (averaged wer latitude and time) as described in the text of $\mathrm{HF}$ (solid line), $\mathrm{CF}_{2} \mathrm{O}$ (dotted line), and CFClO (dashed line).

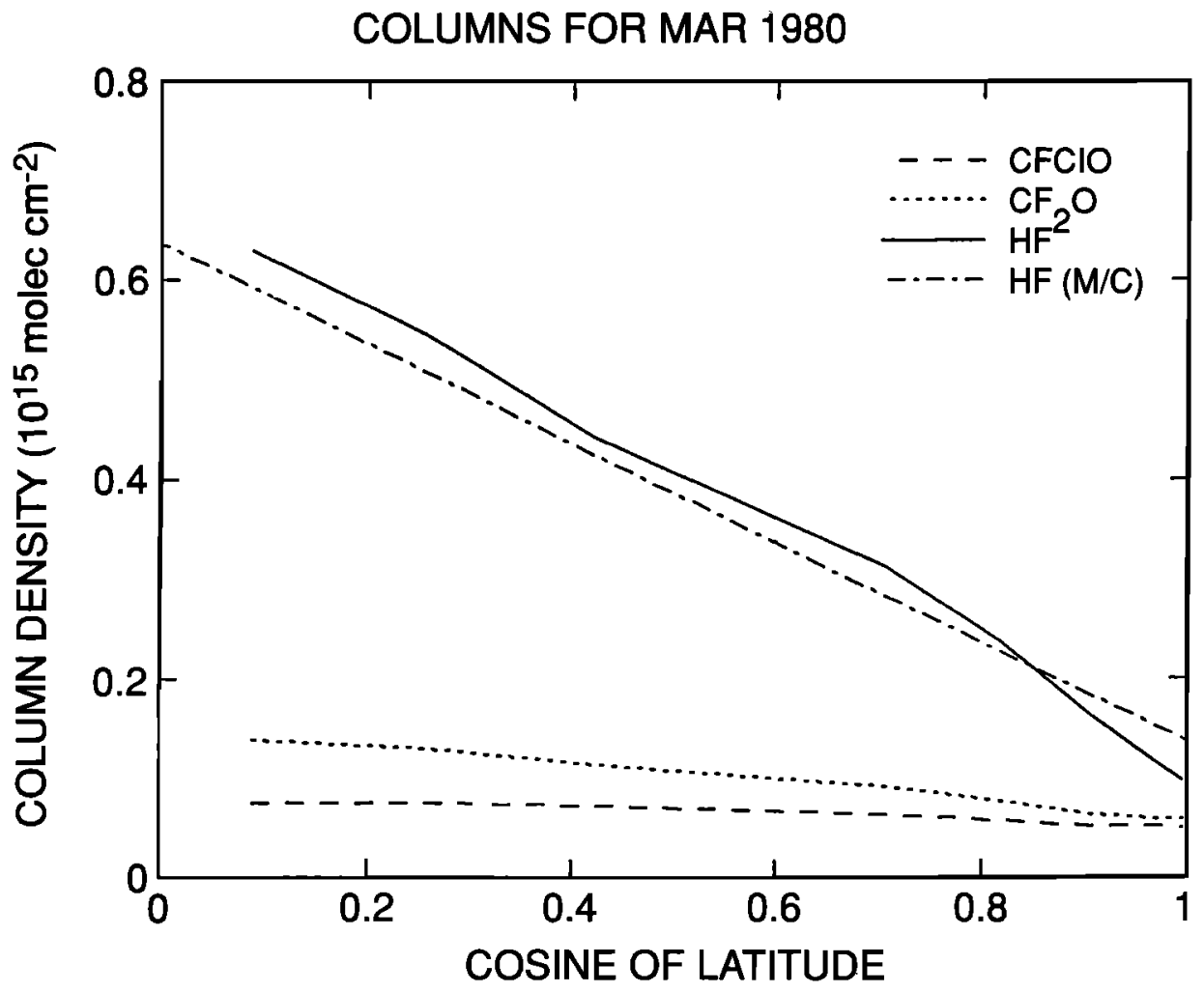

Fig. 5. Latitudinal dependence of vertical column amount of $\mathrm{HF}$ (solid line), $\mathrm{CF}_{2} \mathrm{O}$ (dotted line), and $\mathrm{CFClO}$ (dashed linc) caluclated with 2-D model for March 1980 plotted as column density versus cosine of latitude; that calculated with the expression and constants from Mankin and Coffey [1983] is indicated with a dashed-dotted line. 


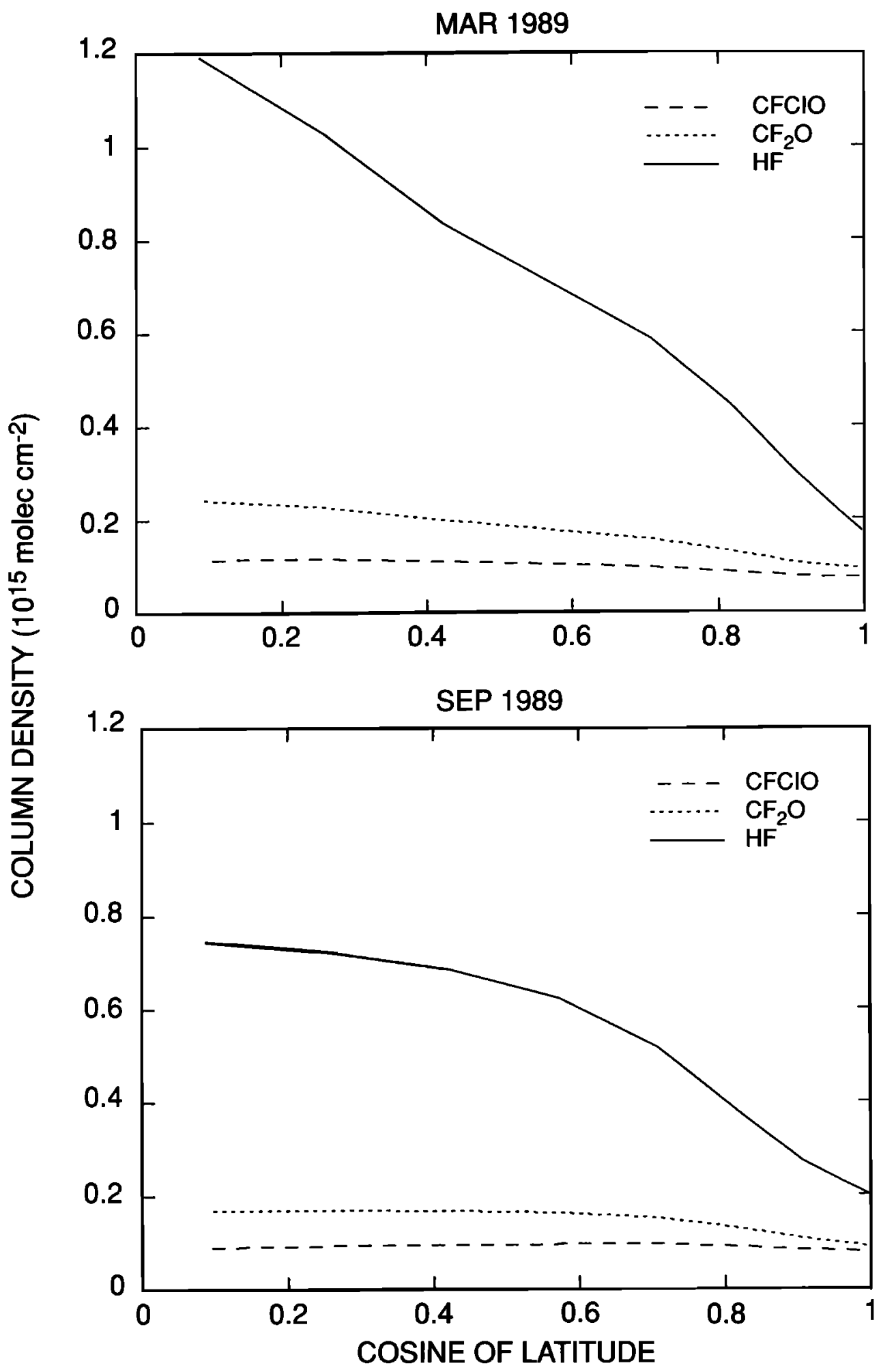

Fig. 6. Latitudinal dependence of vertical columns of $\mathrm{HF}, \mathrm{CF}_{2} \mathrm{O}$, and $\mathrm{CFClO}$ calculated with 2-D model for (a) March (top) and (b) September 1989 with 2-D model. Line types and axes are as in Figure 6.

Any systematic error, especially due to that in the line parameters (estimated at 5-10 percent) should not affect the observed latitudinal distribution in the HF columns.

The latitude dependence of the calculated columns are very similar to that measured by the two groups. For example, the model results for September 1987 have nearly a factor of 2 decrease between $75^{\circ} \mathrm{S}$ and $40^{\circ} \mathrm{S}$ from approximately $0.85-0.4 \times 10^{15}$ molecule $\mathrm{cm}^{-2}$. The calculated values are closer to those measured by the NCAR group than those by the JPL group, but the inability of the model to calculate absolute values of the HF columns in agreement with those measured from the ground (see following section) suggest that this result may not be significant.

Similar results were found for the AASE mission. M. Coffey et al. (private communication, 1990) found columns between 0.3 and $1.1 \times 10^{15}$ molecule $\mathrm{cm}^{-2}$, while G. C. Toon 
et al. (private communication, 1990) found column amounts ranging from $0.6-1.7 \times 10^{15}$ molecule $\mathrm{cm}^{-2}$ between $65^{\circ}$ and $72^{\circ} \mathrm{N}$. There was a noticeable increase in the HF column over the course of the mission from early January to early February. The results of the 2-D model for January 1989 suggested HF columns between 0.8 and $1.0 \times 10^{15}$ molecule $\mathrm{cm}^{-2}$ near $70^{\circ} \mathrm{N}$ with fairly small meridional dependence relative to that seen in the aircraft measurements. Much of the variability in the HF columns measured from the aircraft has been shown to be related to the position of the polar vortex relative to the aircraft position [Mankin et al., 1990a], and this variability cannot be simulated in a 2-D model.

The 2-D model predicts a large increase in the column amounts of $\mathrm{HF}, \mathrm{CF}_{2} \mathrm{O}$, and $\mathrm{CFClO}$ due to increasing amounts of CFCs. This increase is superimposed on a seasonal cycle, whose phase and amplitude are a strong function of latitude. The mid-latitude $\left(45^{\circ} \mathrm{N}\right)$ behavior of the total columns for these constituents is shown in Figure $\mathbf{7}$ for the period from 1977-1990 (this is the period for which HF total column data are avialable from the Jungfraujoch Observatory in Switzerland; see below). The HF and $\mathrm{CF}_{2} \mathrm{O}$ columns are seen to increase by a factor of aproximately 2.5 over this time period, while that of CFClO increases by a factor of two. The calculated $\mathrm{CF}_{2} \mathrm{O}$ increase is somewhat smaller than the factor of 2.75 from October 1979 to April 1989 found by Rinsland et al. [1990] based on balloon flights over New Mexico and vertical profiles determiend in the ATMOS experiment. The seasonal cycle in CFClO is much smaller than that of $\mathrm{CF}_{2} \mathrm{O}$ in spite of their similar column amounts; that of $\mathrm{CF}_{2} \mathrm{O}$ is smaller than that of $\mathrm{HF}$, even allowing for the roughly factor of 3 ratio of the column amounts.

The columns calculated with the 2-D model for calendar year 1990 were fit to an annual cycle in order to determine the amplitude and phase of the seasonal variation as a function of latitude. These are shown in Figure 8 . It is seen that the amplitude of the annual cycle (Figure $8 \mathrm{a}$ ) is largest at high latitudes, especially in the northern hemisphere. The largest amplitude in the Arctic is more than double that in the Antarctic. In the Arctic the largest amplitude is seen closest to the pole $\left(85^{\circ} \mathrm{N}\right)$, while in the Antarctic the maximum amplitude is found away from the pole $\left(65^{\circ} \mathrm{S}\right)$. The amplitude in the tropics is quite small, especially in the southern hemisphere.

The phase of the annual cycle, shown in Figure $8 \mathrm{~b}$, also has important meridional dependence and hemispheric differences. In the northern hemisphere the phase of the seasonal cycle (defined by the maximum in the cycle) is approximately 1.5-1.8 rad north of $25^{\circ} \mathrm{N}$; this corresponds roughly to late March to early April. The phase changes dramatically from $25^{\circ} \mathrm{N}$ across the equator; since the amplitude of the seasonal cycle is very small in the tropics, these quantities are not particularly meaningful there. In the southern hemisphere the phase increasess from -2.5 at $15^{\circ} \mathrm{S}$ to approximately -0.25 at $85^{\circ} \mathrm{S}$, with a region of weak latitude dependence between $45^{\circ}$ and $75^{\circ} \mathrm{S}$.

Several of these variations reflect the assumption of a simple seasonal cycle in the column. This assumption works reasonably well at middle and high northern latitudes but is less appropriate in the tropics and in the Antarctic. As an example, the calculated $\mathrm{HF}$ columns at $75^{\circ} \mathrm{N}, 15^{\circ} \mathrm{N}$, and 85 ${ }^{\circ} \mathrm{S}$ are shown in Figure 9. The smooth annual cycle in $\mathrm{HF}$ at $75^{\circ} \mathrm{N}$ is clear. At $15^{\circ} \mathrm{N}$ there is almost no seasonal variation, and what variation there is seems to have both an annual and a semiannual component. At $85^{\circ} \mathrm{S}$ the annual cycle is again strong, but there is also a noticeable semiannual component.

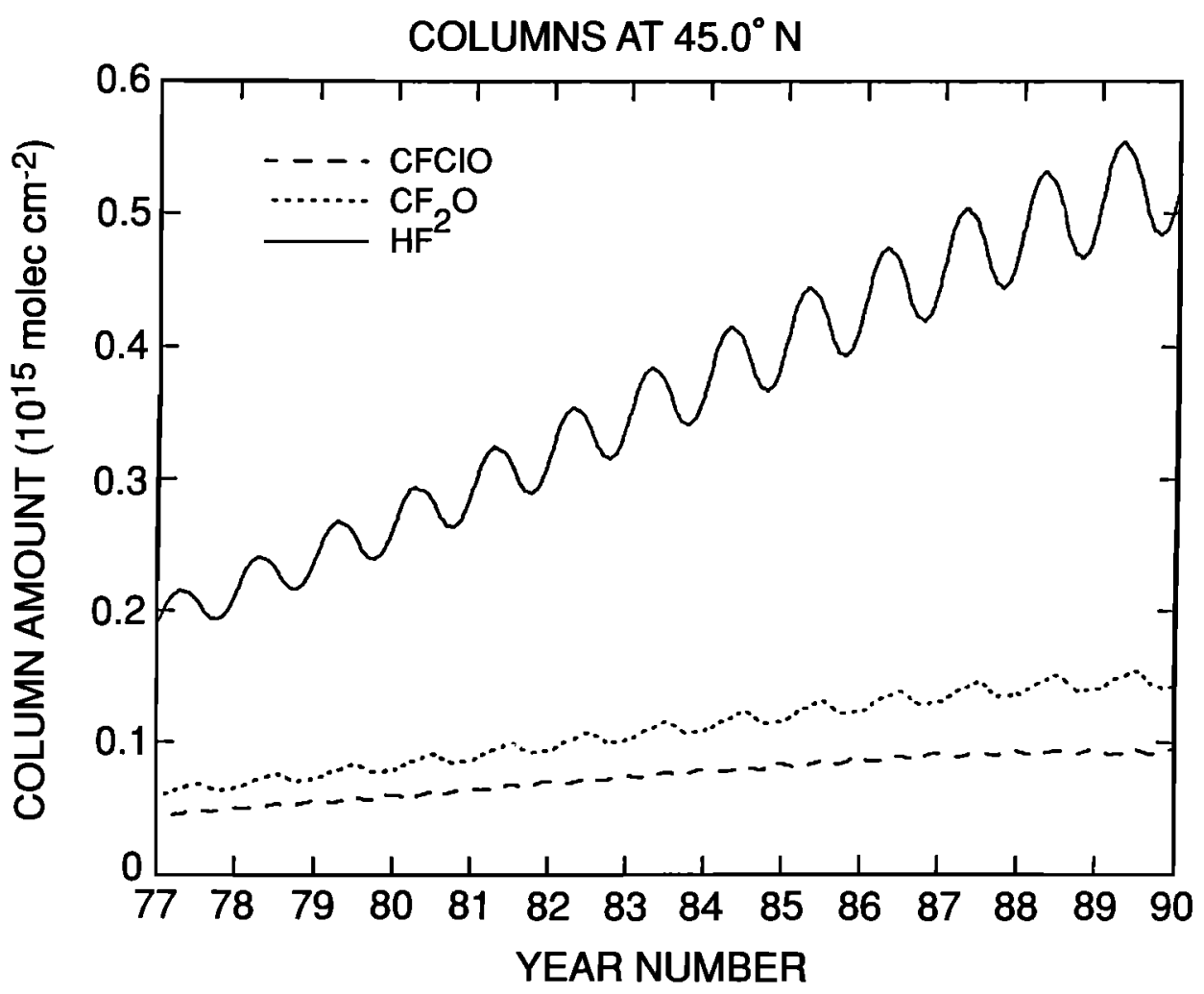

Fjg. 7. Calculated vertical column amount of $\mathrm{HF}$ (solid line), $\mathrm{CF}_{2} \mathrm{O}$ (dotted line), and $\mathrm{CFClO}$ (dashed line) at $45^{\circ} \mathrm{N}$ from $1977-1990$. 

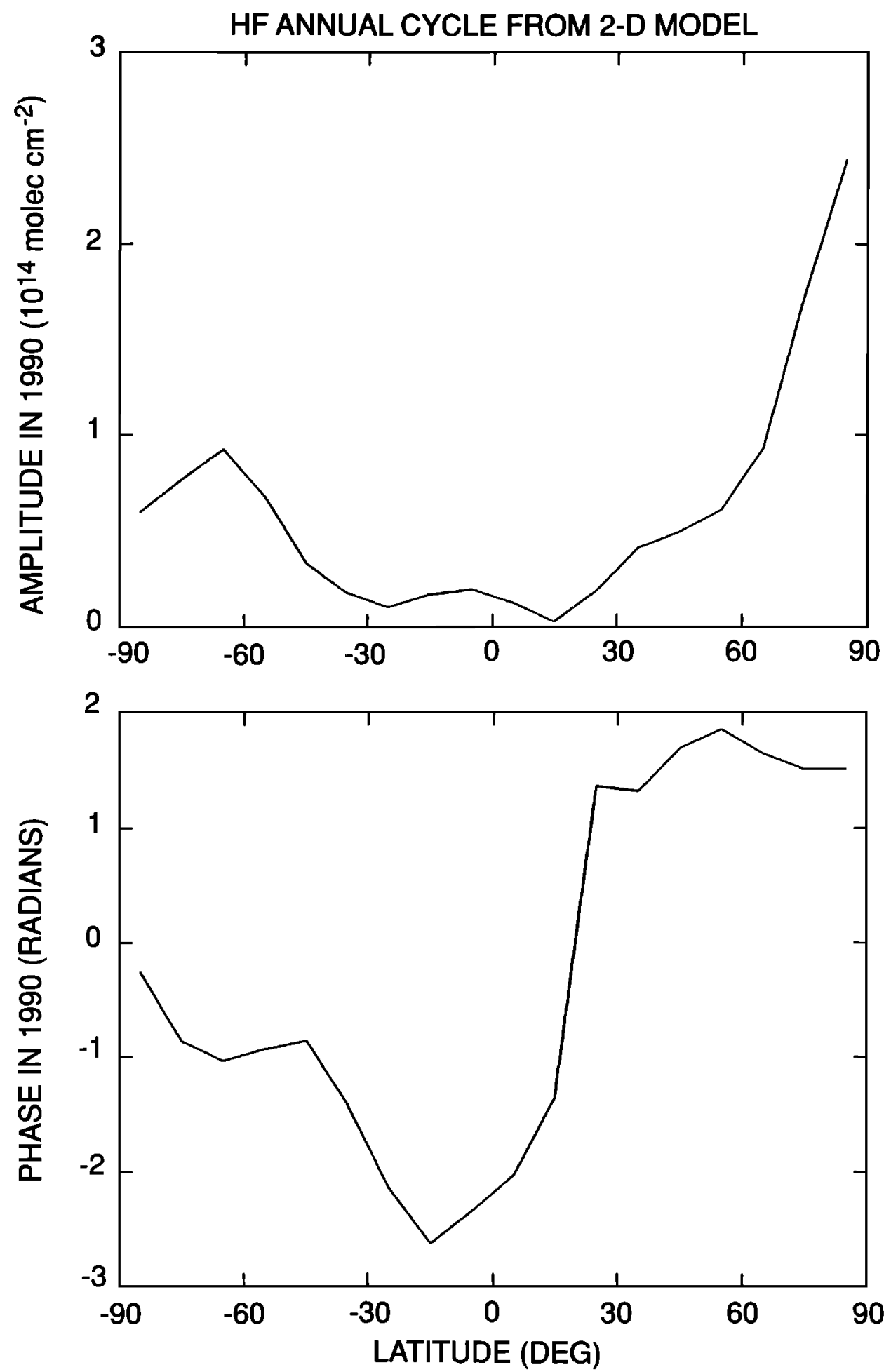

Fig. 8. (a) Calculated amplitude and (b) phase of annual cycle of HF vertical column as a function of latitude for calendar year 1990.

The magnitude of the $45^{\circ} \mathrm{N} \mathrm{HF}$ columns calculated with the 2-D model as well as the relative magnitude of the seasonal cycle are both smaller than that seen from Jungfraujoch. The model output and the data are shown together in Figure 10, along with a curve which was generated by fitting the data (monthly averages) to a function of the form

$y=c_{0} \exp \left(c_{1} t\right)+c_{2} \exp \left(c_{3} t\right) \cos (2 \pi t)+c_{4} \exp \left(c_{5} t\right) \sin (2 \pi t)$

A similar fit was made to the 2-D model output; the coefficients obtained are given in Table 1.
The modeled columns are approximately 60 percent of the measured ones; this factor remains relatively constant throughout the simulation. The relative amplitude of the seasonal cycle in the HF column (the actual amplitude of the seasonal cycle in a given period divided by the mean column for that period) is also smaller in the model than in the data. The absolute amplitudes calculated for 1977 and 1990 are shown in Table 1. By dividing these quantities by the mean colurnns for those years, relative amplitudes of 0.14 

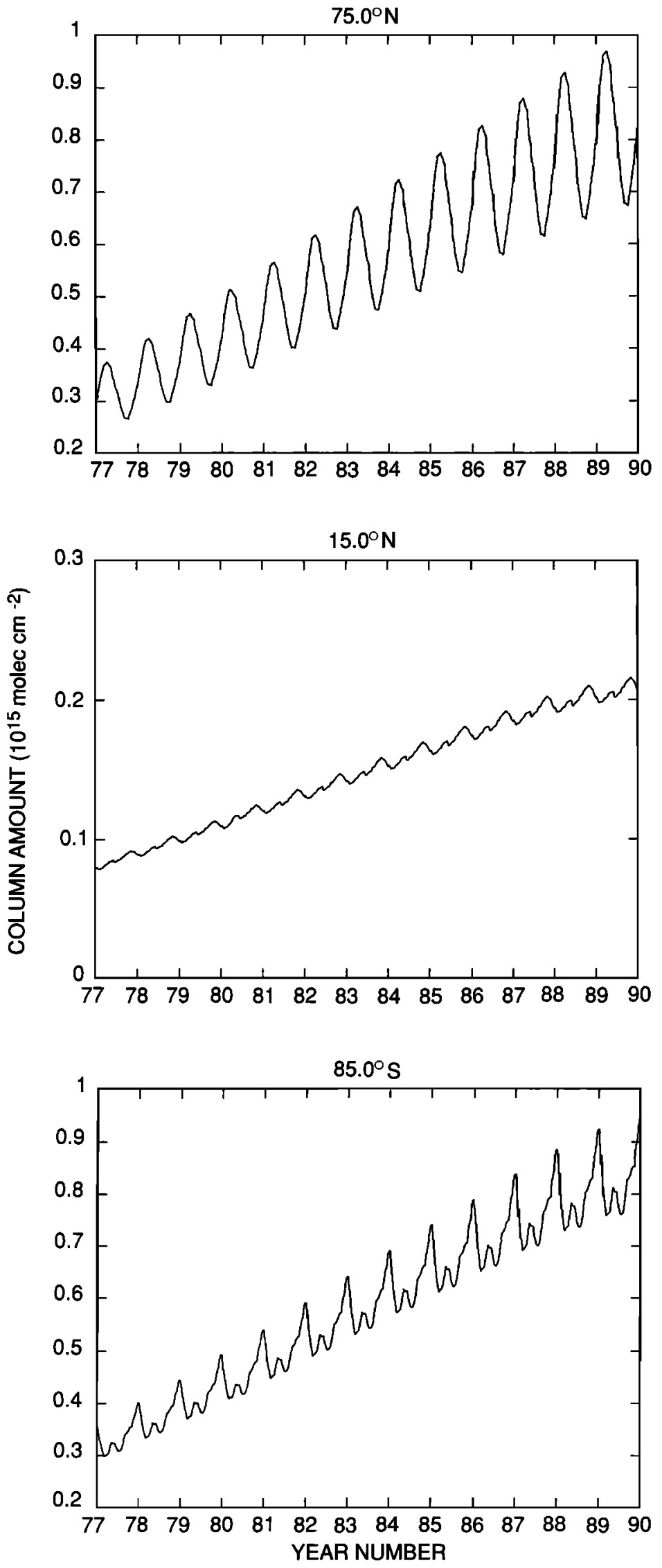

Fig. 10. Munthly averaged HF vertical column over Jungfraujoch (plus signs), fit to annual cycle as described in the text (solid line) and $45^{\circ} \mathrm{N}$ vertical columns calculated with 2-D model for the time period $197 \bar{\imath}-1990$ (dotted line). and 0.07 for the data and model, respectively in 1977 and 0.015 and 0.10 in 1990 were found. We note that the actual variation in the data over the course of a year is frequently much larger than that given by the annual cycle fit to the data.

The phase of the seasonal cycle is, on the other hand, very well represented by the model. The fit to the data suggests a maximum occurring between 2.96 and 2.82 months in the year (corresponding to the years 1977 and 1990), while the fit to the model found maxima at 3.27 and 3.23 months. The difference between these two phases (approximately 1015 days) is quite small, especially considering the limited number of observations and the approximate nature of the fit to the data. The small shift in phase between 1977 and 1990 results from the fact that the fitting procedue generated different growh rates for the cosine and sine terms in the assumed expression. These coefficients were more different for the fit to the data than for the model.

There was one ground-based measurement of the total column of HF made at McMurdo Station, Antarctica, during the first National Ozone Expedition [Farmer et al., 1987]. This measurement, made on October 12, 1986, had a calculated column of $1.8 \times 10^{15}$ molecule $\mathrm{cm}^{-2}$. This large column is slightly above the largest HF column observed from aircraft by Toon et al. [1989] the following year during the AAOE mission; some difference is possible because of the presence of small amounts of HF between the altitude of the McMurdo Station and the aircraft cruising altitude or due to being measured later (a strong increase with time in the HF column was observed during the AAOE mission, which ended September 26).

The 2-D model calculated much smaller HF columns in the Antarctic for October 1987 than observed by Farmer et al. [1987]. That calculated for the latitude of McMurdo (78 ${ }^{\circ} \mathrm{S}$ ) by interpolation of model output at $75^{\circ}$ and $85^{\circ} \mathrm{S}$ was $0.80 \times 10^{15}$ molecule $\mathrm{cm}^{-2}$; this is less than half the observed value. The model also found column amounts of $0.27 \times 10^{15}$ and $0.13 \times 10^{15}$ molecule $\mathrm{cm}^{-2}$ for $\mathrm{CF}_{2} \mathrm{O}$ and $\mathrm{CFClO}$, which together with the calculated HF column implies a total inorganic fluorine column of $1.47 \times 10^{15}$ molecule $\mathrm{cm}^{-2}$. This is still less than the HF column observed by Farmer et al. [1987].

The CFClO measurements of Wilson et al. [1989] are reasonably compatible with the modeled abundances. The largest observed lower stratospheric abundances were 30 pptv, while the mid-latitude 50-mbar values expected are approximately 40 pptv (see Figure 2). The data and model both show $\mathrm{CFClO}$ mixing ratios to increase with altitude. The calculations suggest that in mid-latitudes the CFClO mixing ratios should continue to increase up to approximately 50 pptv at 30 mbar. The model also shows a very strong vertical gradient of the CFClO mixing ratio between approximately 200 and 120 mbar, so that tropospheric air should have very small $\mathrm{CFClO}$ mixing ratios. This is in good agreement with the measurements, which showed no detectable $\mathrm{CFClO}$ in tropospheric air.

\section{Discussion}

The HF columns calculated with the model are smaller than those observed from the Jungfraujoch and from aircraft (JPL group), but are similar in magnitude to those observed from aircraft by the NCAR group. The upper stratospheric HF mixing ratios calculated with the model are very similar 


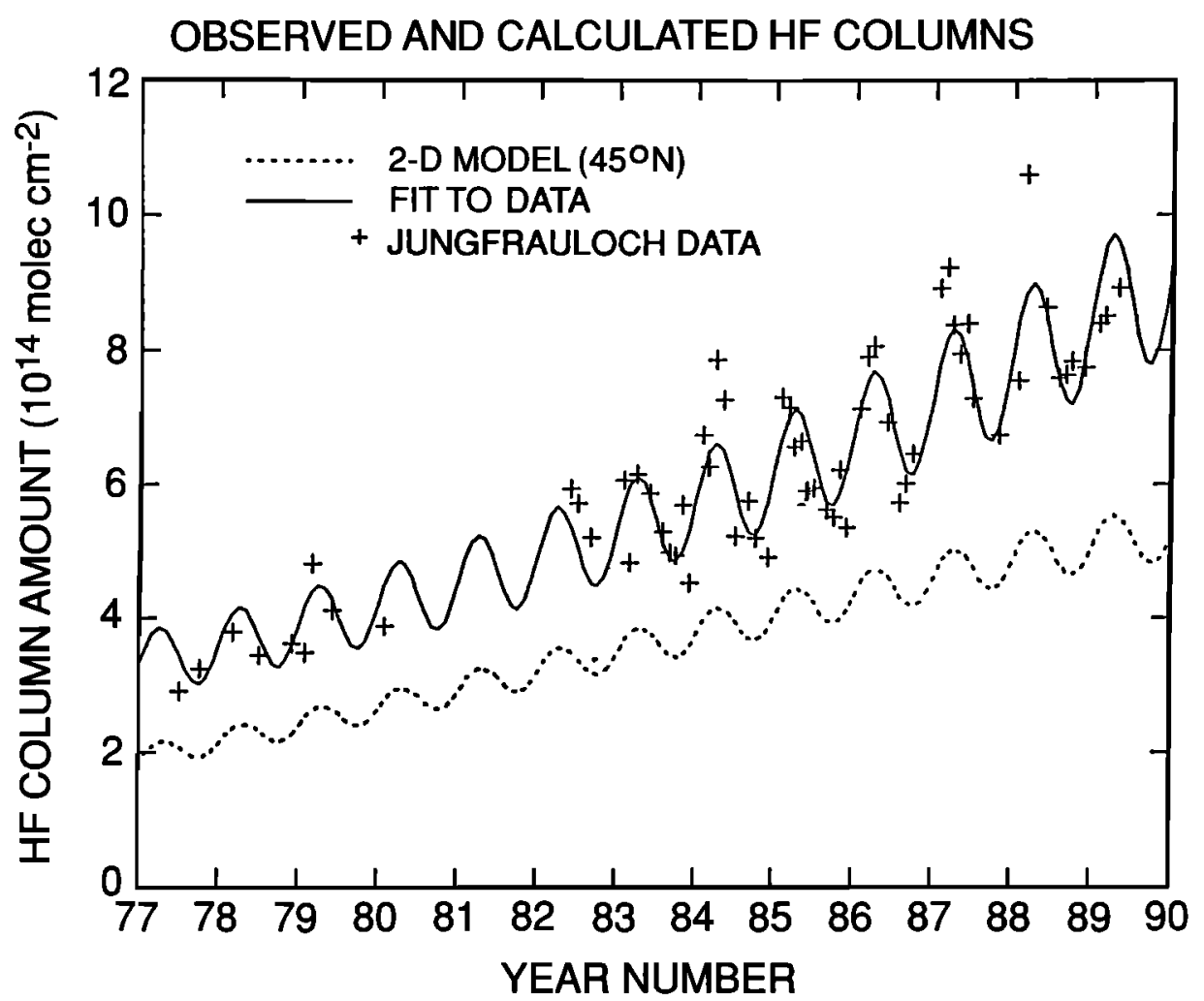

Fig. 10. Monthly averaged HF vertical column over Jungfraujoch (plus signs), fit to annual cycle as described in the text (solid line) and $45^{\circ} \mathrm{N}$ vertical columns calculated with 2-D model for the time period 1977-1990 (dotted line).

to those observed from ATMOS, but the lower stratospheric mixing ratios are much smaller; it is this difference which is responsible for the model calculating smaller columns than typically observed. The model apears to underestimate the magnitude (both relative and actual) of the annual cycle in the HF column at northern mid-latitudes but does an excellent job of predicting the phase of this variation. The model also does a good job of simulating the long-term growth of the HF column, as represented by the similarity in the coefficient $c_{1}$ of exponential growth for the nonseasonally varying term in the fit to the observations and model-calculated columns. The latitudinal dependence of the HF columns is similar to that determined by Mankin and Coffey [1983] in their aircraft flights. The vertical profile of $\mathrm{CF}_{2} \mathrm{O}$ calculated is similar to, but not in precise agreement with,

TABLE 1. Results of Fit of Observed and Modeled HF Columns

\begin{tabular}{llll}
\hline Cuefficient & Units & Data & Model \\
\hline$c_{0}$ & molecule $\mathrm{cm}^{-2}$ & $\mathbf{3 . 3 1 5 2}$ & 2.1868 \\
$c_{1}$ & $\mathrm{yr}^{-1}$ & 0.0780 & 0.0728 \\
$c_{2}$ & molecule $\mathrm{cm}^{-2}$ & 0.0109 & -0.0205 \\
$c_{3}$ & $\mathrm{yr}^{-1}$ & 0.1789 & 0.0824 \\
$c_{4}$ & molecule $\mathrm{cm}^{-2}$ & $\mathbf{0 . 4 6 7 2}$ & $\mathbf{0 . 1 4 3 9}$ \\
$c_{5}$ & $\mathrm{yr}^{-1}$ & 0.0781 & 0.0946 \\
\hline \multirow{2}{*}{ Year/Quantity } & Units & Data & Model \\
\hline 1977 amplitude & molecule $\mathrm{cm}^{-2}$ & 0.4673 & 0.145 \\
1977 phase & months & 2.956 & 3.270 \\
1990 amplitude & molecule $\mathrm{cm}^{-2}$ & $\mathbf{1 . 1 7 4 7}$ & 0.496 \\
1990 phase & months & 2.819 & 3.230 \\
\hline
\end{tabular}

that observed from ATMOS, and there is a strong qualitative similarity between the calculated CFClO amounts in the lower stratosphere and the very limited available data [Wilson et al., 1989].

It is difficult to know how serious the underestimate of HF columns is because of the uncertainty in the absolute magnitude of the HF columns measured by aircraft from different groups. Nevertheless, it is important to consider the possible origins of the underestimate. The overall model scenario seems reasonable, especially given the good highaltitude agreement between the calculated and observed HF mixing ratios and the similarity in the growth of the HF columns. The calculated column is very sensitive to the shape of the calculated profile in the lower stratosphere, which, as pointed out above, is not in very good agreement with the ATMOS data.

Since $\mathrm{HF}$ is the dominant fluorine-containing reservoir species, the underestimate would most likely result from an inaccurate simulation of the breakdown of CFCs in the lower stratosphere. A 25 percent increase in the photolysis rates of $\mathrm{CFCl}_{3}$ and $\mathrm{CF}_{2} \mathrm{Cl}_{2}$ did not make an appreciable difference in the calculated HF profiles in the lower stratosphere. This suggests that if the problem is related to CFC photolysis it may be more a function of the attenuation of ultraviolet radiation in the lower stratosphere (primarily as a result of absorption by molecular oxygen) than of the CFC absorption cross sections. The model would have to markedly overestimate $\mathrm{CF}_{2} \mathrm{O}$ abundances if the underestimate in $\mathrm{HF}$ abundances was due to errors in the treatment of $\mathrm{CF}_{2} \mathrm{O}$ chemistry in the stratosphere. The reasonable agreement between the observed (ATMOS) and calculated $\mathrm{CF}_{2} \mathrm{O}$ profiles suggests that this is not the case. 
Further evidence for this is provided by comparing the ATMOS $\mathrm{HCl}$ profiles for $30^{\circ} \mathrm{N}$ with those calculated with the model; this comparison is shown in Figure 11 (the uncertainties in the ATMOS data are approximately 10 percent throughout the altitude range of the measurements. The 2-D model underestimates the $\mathrm{HCl}$ profile above approximately 70 mbar; the underestimate in the $20-70 \mathrm{mb}$ region should be most serious because of the larger number densities there than at higher altitudes. If the model is underestimating the breakdown of CFCs in the lower stratosphere, underestimates of inorganic chlorine species (including $\mathrm{HCl}$ ) are also expected. The magnitude of the seasonal cycle in ozone at middle latitudes is similarly underestimated [Jackman et al., 1989a].

Some contribution to this underestimate of the magnitude of the seasonal cycle might conceivably be related to the dynamical variability of $\mathrm{HF}$ in the winter. At this time, when planetary waves are at their strongest, air characteristic of higher latitudes, which has higher HF column amounts (see Figure 3) could be found over the Jungfraujoch observatory at some times. Most of the monthly averages are obtained based on data from a limited number of days. For example, the most days in any February for which HF column measurements were made from Jungfraujoch is 5 , while that for March is 14 (in 1989; the next largest number of days was 8 ), and there are no January observations at all. Thus it is possible that some of the wintertime observations may be biased by the presence of air from higher latitudes. If there is a substantial statistical bias in the observations (for example, observations were made more frequently on days with high-latitude air over Jungfraujoch than on days with more normal air), the winter/early spring observations might have unnaturally high values. Analysis of this point requires detailed consideration of stratospheric meteorology during the observing periods; such work is currently underway in our laboratories.

The magnitude of this effect, if real, is unlikely to be sufficiently large to account for the full discrepancy between the relative magnitudes of the seasonal cycle in the model and in the data. The mid-1989 columns observed over Jungfraujoch, typically on the order of $0.9 \times 10^{15}$ molecule $\mathrm{cm}^{-2}$, are characteristic of $70^{\circ} \mathrm{N}$ in the 2-D model (see Figure 3). The 23 degree latitude difference between this latitude and that of Jungfraujoch is larger than one can expect air to be transported sufficiently often for there to be a major effect on the total column.

There may also be a wintertime enhancement of $\mathrm{HF}$ in the stratosphere if there is heterogeneous conversion of $\mathrm{CF}_{2} \mathrm{O}$ to HF on the surface of polar stratospheric cloud particles as has recently been suggested [Wofsy et al., 1990]. If so, this would occur predominantly during January and February and would increase the HF column at the expense of that of $\mathrm{CF}_{2} \mathrm{O}$. In winter, northern mid-latitude $\mathrm{HF}$ columns are typically some 3.5 times those of $\mathrm{CF}_{2} \mathrm{O}$ (see Figure 3 - in 1989 they are $0.5 \times 10^{15}$ and $0.14 \times 10^{15}$ molecule $\mathrm{cm}^{-2}$, respectively). Complete conversion of $\mathrm{CF}_{2} \mathrm{O}$ to $\mathrm{HF}$ would lead to a nearly 60 percent increase in the magnitude of the $\mathrm{HF}$ column. Complete conversion is, of course, unlikely, but the possibility of this conversion is of sufficient importance that further investigation is warranted.

There may also be effects associated with the assumption of zonally averaged and seasonally invariant rainout for both

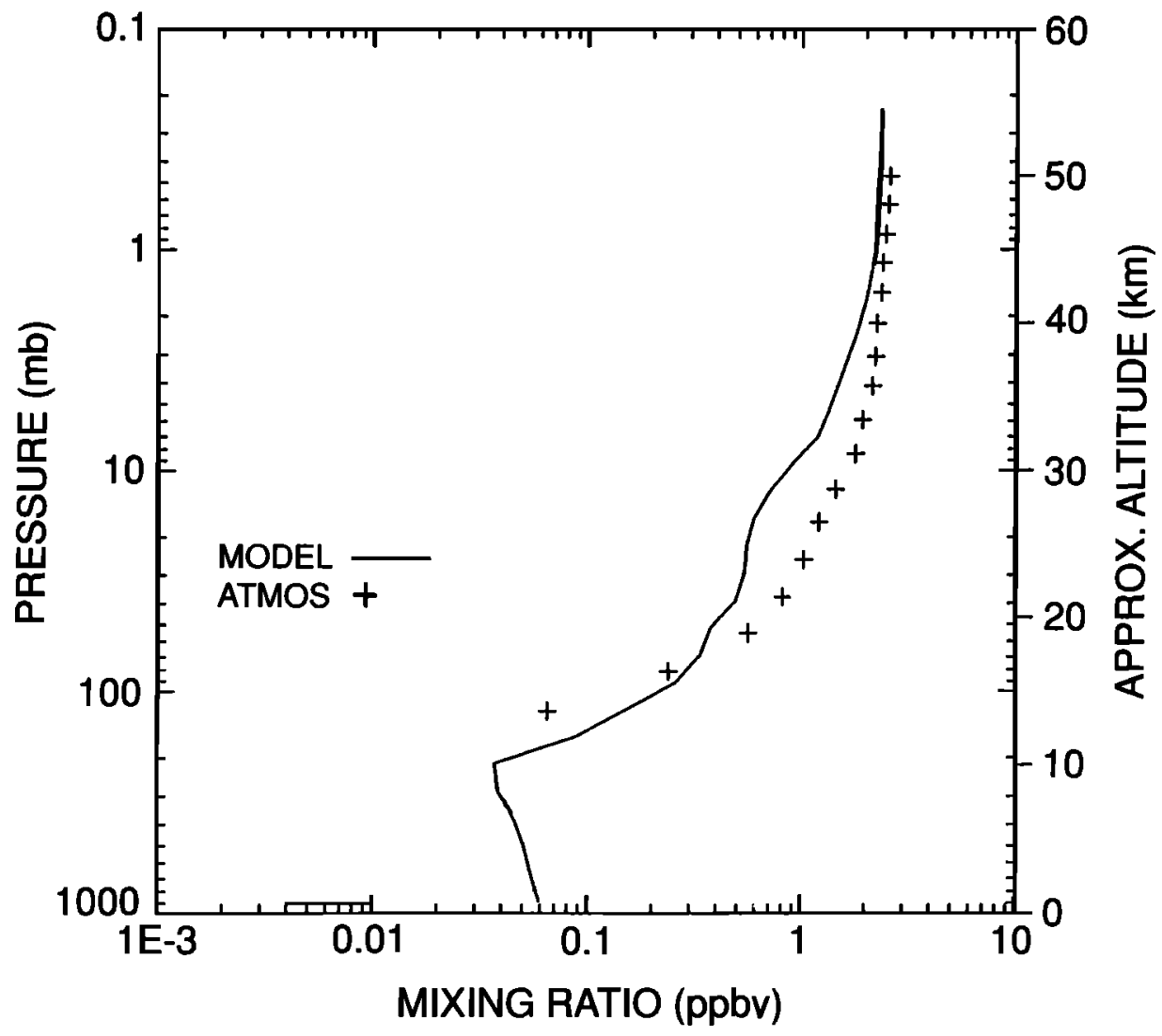

Fig. 11. HCl vertical profile measured by ATMOS at $30^{\circ} \mathrm{N}$ [Zander et al., 1990] and calculated (averaged over latitude and time as discussed in the text) with the 2-D model. 
$\mathrm{HF}$ and $\mathrm{CF}_{2} \mathrm{O}$. If tropospheric rainout is seasonally varying, then the seasonal dependence of the tropospheric columns of $\mathrm{HF}, \mathrm{CF}_{2} \mathrm{O}$, and $\mathrm{CFClO}$ will not be correctly represented. Since the tropospheric HF column is typically assumed to be quite small, the errors associated with this are unlikely to be large, however. In addition, these errors would not affect the seasonal cycle of ozone, which is similarly underestimated in the model.

The model results also suggest that quantum yield for photolysis of $\mathrm{CF}_{2} \mathrm{O}$ substantially smaller than unity is unlikely. Model simulations run with a 0.25 quantum yield for this photolysis, as suggested by DeMore et al. [1987], lead to markedly larger $\mathrm{CF}_{2} \mathrm{O}$ mixing ratios in the middle and upper stratosphere than observed with ATMOS, and to smaller HF mixing ratios. This may be seen in Figure 12, in which a plot analogous to Figure 4 , showing the vertical profiles calculated with the model and those measured by ATMOS are compared. With this 0.25 quantum yield, sizable (greater than $0.1 \mathrm{ppbv}$ ) mixing ratios of $\mathrm{CF}_{2} \mathrm{O}$ persist throughout the stratosphere and into the lower mesosphere. Since the base case model $\left(\mathrm{CF}_{2} \mathrm{O}\right.$ quantum yield of unity) appeared to overestimate upper stratospheric $\mathrm{CF}_{2} \mathrm{O}$ mixing ratios, the subunit quantum yield further enhances this disagreement.

It should be noted that the calculated underestimate of the HF column would be increased if there is appreciable volcanic input of $\mathrm{HF}$ into the stratosphere. The limits suggested by Symonds et al. [1988] for eruption of HF into the stratosphere vary by 2 orders of magnitude. The lower limit is only some 2 percent of the global industrial production of $F$ as halocarbons and would not appreciably alter the calculated HF distribtuion. The upper limit is nearly twice the estimated industrial production, however, so inputs near this limit could appreciably add to the HF burden. The estimated amounts of HF degassed into the troposphere also vary by 2 orders of magnitude but are a factor of 10 larger than for the amount erupted into the stratosphere. The relative contributions of the two terms to total atmospheric HF is very hard to determine. Clearly, more accurate estimates of the volcanic input to the tropospheric and stratospheric HF distribution are needed.

\section{SUMMARY}

A two-dimensional stratospheric chemistry/transport model has been used to simulate the distribution of the key fluorine reservoir species $\mathrm{HF}, \mathrm{CF}_{2} \mathrm{O}$, and $\mathrm{CFClO}$. $\mathrm{HF}$ is found to be the dominant $\mathrm{F}$-containing reservoir species, but $\mathrm{CF}_{2} \mathrm{O}$ and, in the tropics, $\mathrm{CFClO}$ are shown to make an important contribution to the stratospheric fluorine budget. The model does a good qualitative job of simulating the vertical profiles of $\mathrm{HF}$ and $\mathrm{CF}_{2} \mathrm{O}$ as compared to data from the ATMOS instrument, but underestimates the absolute magnitude of the total HF column at northern mid-latitudes as compared to data taken from the Jungfraujoch Observatory in Switzerland. The model also underestimates the magnitude of the seasonal cycle there, but it does simulate well the phase of the seasonal cycle (maximum in late March to early April). The calculated amounts of $\mathrm{CFClO}$ are also

\section{MODEL ( $\phi=0.25)$ vs. ATMOS Data}

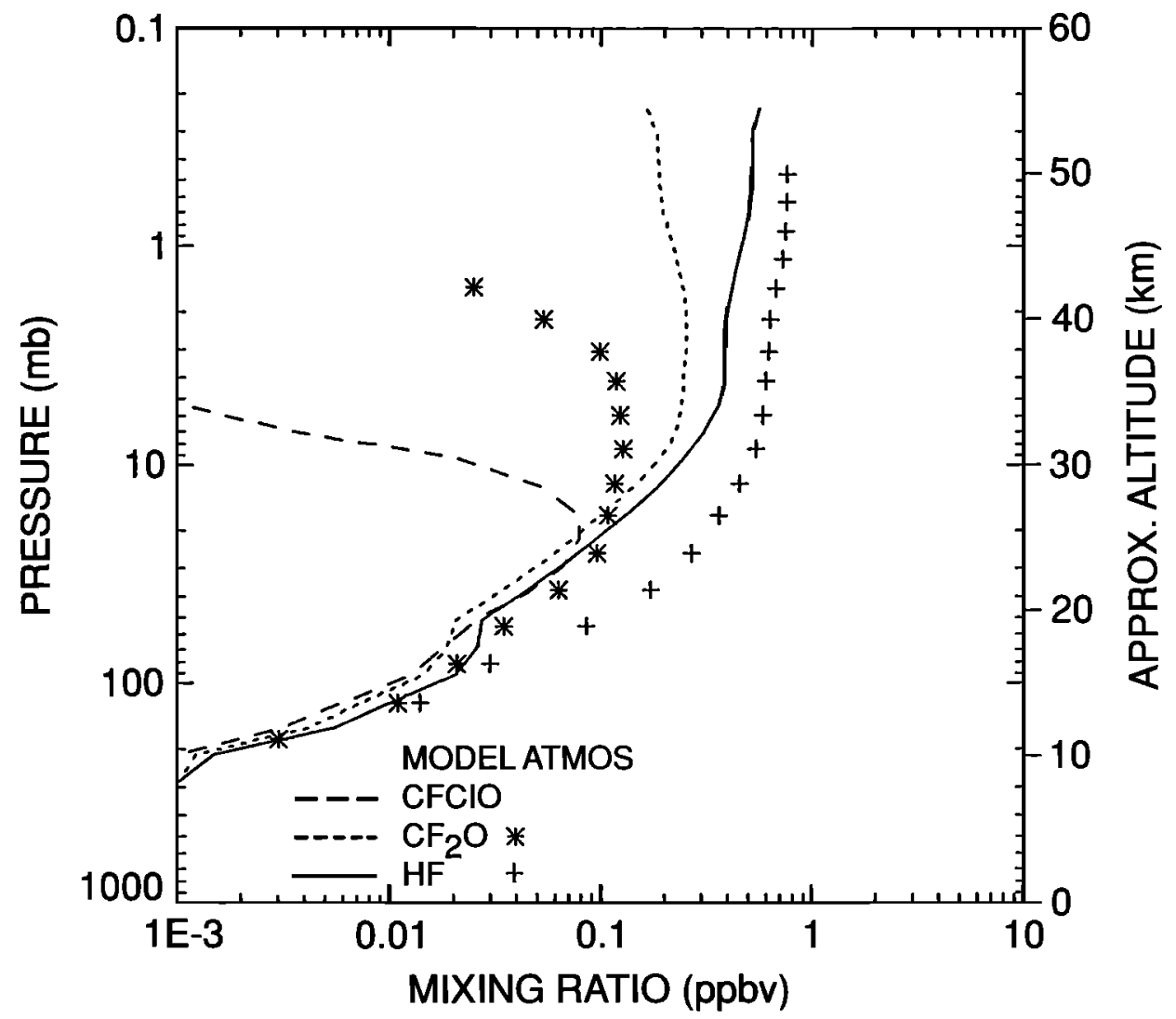

Fig. 12. Vertical profiles of $\mathrm{HF}$ and $\mathrm{CF}_{2} \mathrm{O}$ measured by ATMOS plotted as in Figure 4 along with caluclated profiles for $\mathrm{HF}, \mathrm{CF}_{2} \mathrm{O}$, and $\mathrm{CFClO}$ with photolysis quantum yield for $\mathrm{CF}_{2} \mathrm{O}$ of 0.25 as discussed in the text. 
in reasonable agreement with the limited amounts of data available.

The discrepancy between the calculated and observed HF columns most probably arises from small inaccuracies in the model's treatment of CFC photolysis or vertical transport in the lower stratosphere, leading to underestimates of lower stratospheric HF. The good agreement between calculated and observed upper stratospheric HF mixing ratios suggests that the model accurately represents the total amount of fluorine in the stratosphere. The apparent agreement between the meridional dependence of the HF column measured by Mankin and Coffey [1983] and that calculated here (see Figure 5) suggests that the overall chemistry of HF is well represented as well. The model's underestimate of lower stratospheric $\mathrm{HCl}$ (by comparison with ATMOS data) is consistent with this hypothesis. Major errors in the treatment of $\mathrm{CF}_{2} \mathrm{O}$ and $\mathrm{CFClO}$ chemistry are unlikely to account for this disagreement because of the small contribution they make to the inorganic fluorine budget and the reasonable agreement between the observed and calculated $\mathrm{CF}_{2} \mathrm{O}$ profiles.

It is possible that some of the undrestimate of the magnitude of the annual cycle is related to the suggested heterogeneous conversion of $\mathrm{CF}_{2} \mathrm{O}$ to $\mathrm{HF}$ on the surface of polar stratospheric cloud particles; if this occurs, it would lead to small wintertime enhancements in the HF abundance at the expense of that of $\mathrm{CF}_{2} \mathrm{O}$. The occurrence of substantially sub-unit quantum yield for $\mathrm{CF}_{2} \mathrm{O}$ photodissociation seems unlikely, as that would lead to presence of much larger amounts of $\mathrm{CF}_{2} \mathrm{O}$ in the upper stratosphere than observed by the ATMOS instrument.

If our understanding of these issues is to be improved, additional field and laboratory measurements are needed. Additional measurements of $\mathrm{CF}_{2} \mathrm{O}$ and CFClO are particularly important; the data base of HF measurements will increase dramatically following the launch of the Upper Atmosphere Research Satellite (UARS), on which the Halogen Occultation Experiment (HALOE) will measure vertical profiles at two latitudes per day. Laboratory studies on the possible heterogeneous conversion of $\mathrm{CF}_{2} \mathrm{O}$ to $\mathrm{HF}$ on polar stratospheric cloud particles are also needed, as is a clear determination of the photolysis quantum yield in the ultraviolet photolysis of $\mathrm{CF}_{2} \mathrm{O}$.

Acknowledgments. This is contribution number 66 of the Stratospheric General Circulation with Chemistry Modeling Project (SGCCP) at the Goddard Space Flight Center. We thank Geoffrey Toon and an anonymous reviewer for helpful comments on the manuscript and Leslie Lait for assistance with the preparation of camera-ready copy.

\section{REFERENCES}

Baulch, D. L., R. A. Cox, R. F. Hampson, Jr., J. A. Kerr, J. Troe, and R. T. Watson, Evaluated kinelic and photochemical data for atmuspheric chemistry, J. Phys. Chem. Ref. Data, g, $295-471,1980$.

Carli, B., and J. H. Park, Simultaneous measurement of minor stratuspheric constituents with emission far-infrared spectruscopy, J. Geophys. Res., 93, 3851-3865, 1988.

Chu, W. P., M. T. Coffey, W. S. Heaps, J. A. Kaye, M. P. McCormick, R. S. Stolarski, and R. Zander, Other trace gases, in Ozone Trends Panel Report, edited by R. T. Watson, pp. 571-593, NASA, Washington, D. C., 1990.

Coffey, M., T., W. G. Mankin, and A. Goldman, Airborne measurements of stratospheric constituents over Antarctica in the austral spring 1987, II, Halogen and nilrogen trace gases, $J$. Geophys. Res., 94, 16,597-16,613, 1989.

Crutzen, P. J., I. S. A. Isaksen, and J. R. McAfee, The impact of the chlorucarbon industry on the ozone layer, J. Geophys. Res., 83, 345-363, 1978.

Dellore, W. B., M. J. Molina, S. P. Sander, D. M. Golden, R. F. Hampson, M. J. Kurylo, C. J. Howard, and A. R. Ravishankara, Chemical kinetics and photochemical data for use in stratospheric modeling. $J P L P u b l ., 87-41,1987$.

Douglass, A. R.. C. H. Jackman, and R. S. Stolarski, Comparison of model results transporting the odd nitrogen family with results transperting separale odd nitrogen species, $J$. Geophys. Res., 94. 9862-9872, 1989.

Douglass, A. R., R. B. Rood, R. S. Stolarski, M. R. Schoeberl, M. H. Pruffilt, J. J. Margitan, M. Loewenstein, J. R. Podolske, and S. E. Strahan, Global three-dimensional constituent fields derived frum profile data, Geophys. Res. Lett., 17, 535-538, 1990.

Farmer, C. B.. G. C. Toon, P. W. Schaper, J.-F. Blavier, and L. L. Lowes, Straluspheric trace gases in the spring 1986 Antarctic atmusphere, Nalure, 929, 126-130, 1987.

Francisco, J. S., A. N. Goldstein. and I. H. Williarns, Dissociation dynamics of FCO and HCO radicals, J. Chem. Phys., 89, 3044$30.49,1988$.

Girard, A.. G. Fergant, I. Gramont, O. Lado-Bordowsky, J. Lurent. S. Le Boiteux, M. P. Lemaitre, and N. Louisnard, Latitudinal distribution of 10 stratospheric species deduced from simultancius spectroscopic measurements, J. Geophys. Res., $88,5377-53392,1983$.

Jackman. C. H., A. R. Douglass, P. D. Guthrie, and R. S. Stolarski, '1 lie sersitivity of tolal ozone and ozone perturbation scenarios in a two-dimensional model due to dynamical inputs, J. Geophys. Res., 94, 9873-9887, 1989 a.

Jackman, C. II,, R. K. Seals, Jr., and M. J. Prather, TwoDimensional Intercomparison of Stratospheric Models, NASA Conf. Publ. 3042, 19896.

Karcher, F., M. Amodei, G. Arrnand, C. Besson, B. Dufour, G. Froment, and J. P. Mever. Simultaneous measurements of $\mathrm{HNO}_{3}, \mathrm{NO},, \mathrm{HCl}, \mathrm{O}_{3}, \mathrm{~N}_{2} \mathrm{O}, \mathrm{H}_{2} \mathrm{O}$ and $\mathrm{CO}$ and their latitudinal variatiurns deduced from air-borne infrared spectrometrs, $A n n$. Geophys.. (i. 425-4 14, 1988.

Kaye, J. A.. A. R. Douglass, R. B. Rood, R. S. Stolarski, P. A. Newmall. D. J. Allen, E. M. Larson, M. T. Coffer; W. G. Mankin. and G. C. Toon, Three dimensional simulation of hydrugell chluride and hydrengen fluoride during the Airborne Arctic Stratuspheric Expedition, Geophys. Res. Lett., 17, 539$5+2,1990$.

Lesclaux. IR., and E. Caralp, Determination of the rate constints for the reactions of $\mathrm{CFCl}_{2} \mathrm{O}_{2}$ radical with $\mathrm{NO}$ and $\mathrm{NO}_{2}$ by laser phutolysis and time resolved mass spectrunetry, Int $J$. Chem. K2n., 16. 1117-1128. 1984.

Lesclaux, R.. I . Caralp, A. M. Dognon, and D. Cariolle, The rate of formalion of halomethyl peroxy nitrates in the stratosphere and thejr mossible role as temporary reservoirs for $\mathrm{ClO}_{\mathrm{x}}$ and NO $_{x}$ species. Geophys. Res. Lett., 19, 933-936, 1986.

Mankin, W. C.., and M. T. Coffey, Latitudinal distributions and lemporal changes of stratospheric $\mathrm{HCl}$ and $\mathrm{HF}, J$. Geophys. Res., 88. 10.776-10,78-1, 1983.

Mankin, W. (i., M. T. Coffey, A. Goldman, M. R. Schoeberl, L. R. Lait, and P. A. Newman. Airborne measurements of stratospheric constiluents over the Arctic in the winter of 1989, Geophys. Res. Lell., 17, -173-176. 1990 a.

Mankin, W. G.. M. T. Coffey, K. V. Chance, W. A. Traub, B. Carli, I: N Mcncaraglia, S. Piccioli, I. G. Nolt, J. V. Radostitz, R. Zander. G. Roland, D. W. Johnson, G. M. Stokes, C. B. Farmer, and R. K. Seals, Intercomparison of measurements of stratospheric hydrogen fluoride, J. Atmos. Chem., in press, 19906.

Mloore, S. B., and R. W. Carr, Kinetics of the reaction of $\mathrm{CF}_{2} \mathrm{ClO}_{2}$ radicals with nitrogen dioxide, J. Phys. Chem., 94, 1393-1-1(1), 1990.

Park, J. H., D. J. W. Kendall, and H. L. Buijs, Stratuspheric HF mixing ratio profiles in the northern and southern hemispheres, J. Geophys. Res., 89, 11,645-11,653, 1984 .

Raper, O. F. et al., lnfrared spectroscopic measurements of halogenated sink and reservoir gases in the stratosphere with the ATNIOS instrument, J. Geophys. Res., 92, 9851-9858, 1987. 
Rebbert, R. L... and P. J. Ausloos, Photodecomposition of trichlorofluoromethane and dichlorodifluoromethane, J. Photochem., 4, 4101-13.1, 1975.

Rinsland, C. P., R. Zander, L. R. Brown, C. B. Farmer, J. H. Park, R. H. Norton, J. M. Russell III, and O. F. Raper, Detection of carbonvl fluuride in the stratosphere, Geophys Res. Lett., 13, 769-772, 1986 .

Rinsland, C. P., A. Goldman, F. J. Murcray, R. D. Blatherwick, J. J. Kusters. D. G. Murcray, N. D. Sze, and S. T. Massie, Longterm trends in the concentration of $\mathrm{SF}_{6}, \mathrm{CHClF}_{2}$, and $\mathrm{CF}_{2} \mathrm{O}$ in the lower stratosphere from analysis of high resolution infrared solar wccultation spectra, J. Geophys. Res., 95, 16,477-16,490, 1990 .

Rood, R. B., D. J. Allen, W. E. Baker, D. J. Lamich, and J. A. Kaye. The use of assimilated stratospheric data in constituent transpurt calculations, J. Atmos. Sci., $66,687-701,1989$.

Solomon, S., and R. R. Garcia, On the distributions of longlived tracers and chlorine species in the middle atmosphere, $J$. Geophys. Res., 89, 11,633-11,644, 1984.

Stolarski, R. S., and R. D. Rundel, Fluorine photochemistry in the stratisphere, Geophys. Res. Lett., 2, 433-434, 1975.

Symonds, R. B., W. I. Rose, and M. H. Reed, Contribution of Cland F-bearing gases to the atmosphere by volcanoes, Nature, 334, 415-118, 1988.

Sze, N. D., Stratospheric fluorine: A comparison between theory and measurements, Geophys. Res. Lett., 5, 781-783, 1978.

Toon, G. C., C. B. Farmer, L. L. Lowes, P. W. Schaper, J.-F. Blavier, and R. H. Norton, Infrared aircraft measurements of stratospheric composition over Antarctica during September 1987, J. Cicophys. Res., 94, 16,571-16,596, 1989.

Wilson, S. R.. G. Schuster, and G. Helas. Measurements of
COFCI and $\mathrm{CC}_{2} \mathrm{O}$ near the tropopause. in Ozone in the Atmosphere. edited by R. D. Bı,jkov and P. Fabian, pp. 302-305, Deepak. llampton, Va., 1989.

Wine, P. II.. and A. R. Ravishankara, Reactive and non-reactive quenching a $O\left({ }^{1} D\right)$ by $\mathrm{CF}_{2} O$. Chem. Phys. Lett., 96, 129-132, 1983.

World Mletweurolugical Organization (WMO), Sczentific Assessmenl of Stralospheric Ozone: 1989, Geneva, 1990.

Wofsy, S. C.. J. H. Yatleau, R. J. Salawitch, M. B. MIcElroy, G. C. Tooll. W. G. Mankin, and M. T. Coffey, Heterogener,us coversion of $\mathrm{CF}_{2} \mathrm{O}$ to $\mathrm{HF}$ on polar stratospheric clouds, Geophys. Res. Lell., 17, 461-464, 1990.

Zander, R.. Recent observations of $\mathrm{HF}$ and $\mathrm{HCl}$ in the upper stratusphtere, Geophys. Res. Lett., 8, 413-416, 1981.

Zander, R., G. Roland, L. Delboujlle, A. Sauval, C. B. Farmer and $\mathrm{R}$. H. Norton, Nonitoring of the integrated column of hydrogen flucride above the Jungfraujoch station since 1977 - The HF/HCl column ratiu, J. Almoos. Chem., 5, 386-394, 1987.

Zander, R. M. R. Gunson, J. C. Foster, C. P. Rinsland, and J. Namkung. Stratospheric $\mathrm{ClONO}_{2}, \mathrm{HCl}$, and $\mathrm{HF}$ concentration profiles derived from ATNIOS Spacelab 3 observations - An update, J. Geophys. Res., 95, 20,519-20,525, 1990.

A. R. Douglass, J. A. Kaye, C. H. Jackman, and R. S. Stolarski, Code 916, NASA/Goddard Space Flight Center, Greenbelt, MD 20771. G. Roland and R. Zander, Institute of Astrophysics, University of Liège, B-4200, Liège-Ougrée, Belgium.

(Received November 8, 1990; revised April 24, 1991; accepted April 24,1991 ) 